\title{
Latest Developments in Modeling and Characterization of Joining Metal Based Hybrid Materials
}

\author{
Shahin Khoddam,* Liang Tian, Thaneshan Sapanathan, Peter D. Hodgson, \\ and Abbas Zarei-Hanzaki
}

\begin{abstract}
Advanced materials consist of several materials systems that exhibit complementary properties for multi-purpose applications. Joining of dissimilar materials is a critical and challenging advanced manufacturing technique to develop novel hybrid materials with properties fully transferred. The "bonding strength" of a joint is crucial for its integrity and performance. The bonding strength is affected by a range of parameters that can be better understood, controlled, and optimized via both experimental and analytical approaches. In this paper, the authors review the theoretical and experimental studies of the interface inside several metal based composites. The scope includes interface bonding's critical parameters, characterization techniques of joining processes, potential applications, and their future perspectives. The review is significant to develop advanced manufacturing techniques for heterogeneous materials and to design innovative heterogeneous systems for various medical, electrical, electronics, industrial, and other daily life applications that involve the broad range of "joining" processes.
\end{abstract}

\section{Introduction}

The evolution of human civilization has been driven by the invention of novel dissimilar materials with improved overall properties in a wide range of applications in aerospace, automotive, robotics, and energy. Metals have played an important role in society since the Bronze Age. Joining metal

Dr. S. Khoddam, Prof. P. D. Hodgson

Institute for Frontier Materials

Deakin University

Geelong, Australia

E-mail: S.Khoddam@deakin.edu.au

Dr. L. Tian

Department of Materials Science and Engineering

University of Michigan

Ann Arbor, USA

Dr. T. Sapanathan

Institute of Mechanics

Materials and Civil Engineering

Université catholique de Louvain

B-1348 Louvain-la-Neuve, Belgium

Prof. A. Zarei-Hanzaki

School of Metallurgy and Materials Engineering

College of Engineering

University of Tehran

Tehran, Iran

DOI: 10.1002/adem.201800048 based hybrid materials to achieve improved properties is a challenge, due to a lack of available technologies.

Therefore, devising novel techniques to join materials is a cornerstone for many advanced manufacturing techniques and is critical to fabricate advanced hybrid materials with unique properties.

Hybrid materials, consisting of at least two constituents that interact at the nanometer scale, are essential for industrial applications where a single material cannot meet the requirements. ${ }^{[1,2]}$ A clear advantage of hybrid materials is the integration of the dissimilar properties of their individual components into a single material. They are the most exciting material systems for technological innovations due to the emergent new properties arising from the interaction of two constituents. As the interaction transitions from microscopic to nanoscale, the physical and chemical properties of these materials change substantially with respect to their individual constituents. They are classified based on their structure as composite, lattice, sandwich, and segments, or by their chemical interactions, such as van der Waals, hydrogen bonding, coordination bonding, or covalent bonding. Hybrid materials are fabricated by combining a wide range of material types, including metals, ceramics, polymers, elastomers, and glass, to form composites. Specific examples include metal matrix composite $(\mathrm{MMC})^{[3-6]}$, carbon nanotube polymer/ceramic/metal composite ${ }^{[7-11]}$, and cermet (ceramic and metal).

Hybrid metals can be classified into metallic alloys and metallic composites. Alloys are typically made by melting the mixture of two or more elements or mechanical ball milling of two metallic elemental powders to form a solid solution alloy phase. Metallic composites are formed by solid state techniques, such as metal joining processes, powder metallurgy ${ }^{[12]}$ and deformation processes (i.e., extrusion), cladding process of two metals, ${ }^{[13]}$ advanced additive manufacturing technology, ${ }^{[14]}$ liquid state stir or squeeze casting and spray deposition techniques; and vapor deposition techniques. Bimetallic hybrid materials contain the desired desirable properties of the two metallic materials. ${ }^{[15]}$ For example, these composite materials offer many different excellent properties, such as high specific strength, good corrosion resistance, and high electrical and thermal conductivity. ${ }^{[16]}$ Nowadays, cladded materials are used 
widely in many industries, including automotive, ${ }^{[17]}$ medical, ${ }^{[18]}$ aerospace ${ }^{[19]}$ chemical and oil refinery. ${ }^{[20]}$ The hybrid metals can be joined using a third medium (e.g., a polystyrene foam) to make a wire-dielectric. ${ }^{[21]}$

The economic, high yielding, energy efficient, and environmentally benign manufacturing techniques used to create these composite materials are attracting widespread attention and being actively researched. The challenges of joining metalsbased materials primarily lies in maintaining atomic contact at the macroscopic level and clean surfaces free of contaminants. ${ }^{[22]}$ Metals tend to attract contaminants such as oxygen and moisture during processing. For example, Al powders easily absorb moisture and oxygen onto their surface to form thin hydroxide layers, which prevent atomic contact and suppress atomic diffusion. This hinders formation of the metallurgical bonds with other $\mathrm{Al}$ powders during powder metallurgy processes.

This review focuses on "metal-composites"; that is, hybrids with at least two constituent parts, one being a metal necessarily. The scope of this review is to present two approaches to model the bond strength and to review selected fabrication and joining methods and their characterization, applications and future trends.

\section{Structural Modeling of Metal-Composites}

For a metal-composite to be utilized as a structural component, it has to satisfy the minimum requirements of service conditions such as yield strength, fatigue, creep resistance and excellent corrosion resistance. For non-structural applications, the service conditions include thermal (extreme temperature), electrical (high voltage), electromagnetic condition (strong electromagnetic radiation), and radiation condition (high radiation), which require these composites to exhibit the necessary damage resistance to these extreme environments. ${ }^{[23,24]}$ In the case of a metal-metal composite, "plastic deformation induced joining" can improve properties of the individual metals by locally engineering their microstructure.

Deformation processing of metal-metal-composites $(\mathrm{DMMCs})^{[25]}$ is a common method of effective joining. ${ }^{[26]}$

From a design perspective of structural materials, it is desirable to model the bonding strength and evaluate various parameters that can affect the bonding strength in the metal composite to guide the design of advanced metal composites with effective joining to achieve fully optimized properties. Developing such models needs a detailed and mechanistic understanding of the mechanical behavior of both constituent components and their interfaces. Models of two common bonding types are reviewed here, including "nano-mechanical" and "micro-mechanical" models. ${ }^{[27]}$

\subsection{Nano-Mechanical Approach}

Nano-mechanical models are defined as models that try to explain the bonding between crystallites by the micro or nanoscale constituents of a metal-metal composite and especially the significant area of interfaces. The interfacial

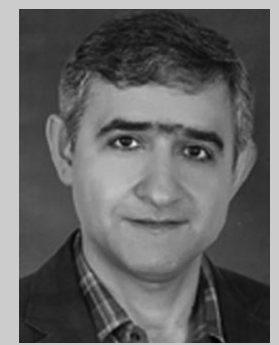

A/Prof. Shahin Khoddam has a strong track record on e-design, developing and solution of multidisciplinary models for physical simulation in engineering. Examples of these are inverse characterization of materials and processes, closed form solutions for SRX, friction and barrelling during hot torsion, high pressure torsion and compression

tests, respectively, which are essential to characterize, control and optimize parameters of the physical process. He has developed several mechatronics systems and numerous dedicated FE codes for numerical-experimental characterization.

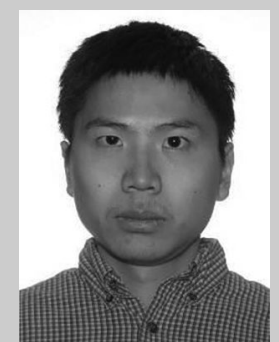

Dr Liang Tian is a postdoctoral research fellow at University of Michigan, Ann Arbor. He was awarded his Ph.D in Materials Science and Engineering in 2015, M. Eng in Engineering Mechanics in 2012. His research interests are powder metallurgy, lightweight metal matrix composite, interfaces and surfaces, mechanical and electronic properties, nano-crystalline materials, computational materials science, first principles alloy thermodynamics.

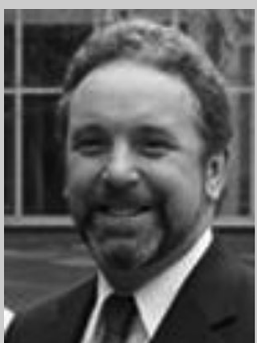

Professor Peter Hodgson, DVC-R Deakin University, has made a number of major contributions to a broad range of research fields. He is the leading researcher in Australia in the thermomechanical processing of steel and has established the most sophisticated laboratory to study metal from melting through thermomechanical processing to property evaluation and microstructure characterization. In the thermomechanical processing of steels, he is internationally renowned for the development of microstructure models for hot rolling.

bonding strength is primarily determined by how the individual constituent mechanically interacts with the interfaces. In the Nano-mechanical modeling approach, models of two bonding types, that is, bonding between two different metal phases (heterophase interface) and bonding between the same metal crystallites, are reviewed.

\subsubsection{Heterophase Interface in a Metal-Composite}

Interfaces of crystalline materials can be homophase (i.e., grain boundary separating the same crystals but with different 
orientation) or heterophase (i.e., interphase boundary separating different crystals with different atomic structure and/or chemistry as well as orientation). The properties of interfaces are primarily determined by their interactions with the defects such as zero-dimensional point defects (i.e., interstitials and vacancies), one-dimensional dislocations or two-dimensional twin boundaries. ${ }^{[28,29]}$

The interphase boundary is of great interest in metal-metal composites due to its extraordinary properties in improving strength and transport properties and absorbing radiation damage. Interfaces, acting as a strong barrier to dislocation motion and transmission, can substantially strengthen metallic composites above the level estimated by the rule of mixtures. ${ }^{[26,30]}$ This is especially true when the interface spacing decreases to the nanometer scale so that the interface area per unit volume increases dramatically. For example, Bevk et al. ${ }^{[30]}$ studied $\mathrm{Cu}-18$ vol\% $\mathrm{Nb}$ composites with a reported ultimate tensile strength of $2200 \mathrm{MPa}$. This strength is four times higher than that predicted by rule of mixtures of $\mathrm{Cu}$ and $\mathrm{Nb}$. Tian et al. ${ }^{[13,16,31]}$ studied the microstructure strength relation in Al-Ca composites and found that the strength value $476 \mathrm{MPa}$ of Al-20 vol\% Ca composite is four times higher than the predicted strength by the rule of mixtures of pure $\mathrm{Al}$ and $\mathrm{Ca}^{[32,33]}$ The Al-Ca composite processed by power metallurgy ${ }^{[34]}$ and severe plastic deformation (as demonstrated in Figure 1), has a high strength, ${ }^{[25]}$ high electrical conductivity ${ }^{[16,35]}$ that is ideal for a high voltage power transmission electrical conductor. ${ }^{[36,37]}$ Trybus and Spitzig ${ }^{[38]}$ studied a rolled and wire-drawn $\mathrm{Cu}-\mathrm{Nb}$ composite. The strength in the rolled and wire drawn $\mathrm{Cu}-\mathrm{Nb}$ both increased with deformation. Rolled $\mathrm{Cu}-\mathrm{Nb}$ showed a weaker strength dependence on filament spacing than that of the wire-drawn $\mathrm{Cu}-\mathrm{Nb}$ though both followed the Hall-Petch relationship. This weaker dependence could be a consequence of the well-aligned planar filaments being less effective barriers to lattice dislocation motion than the convoluted filaments of wire drawn $\mathrm{Cu}-\mathrm{Nb}$. Similar strengthening effects were observed in a series of $\mathrm{Cu}$ matrix refractory metal composites studied by Verhoeven, Spitzig, and their colleagues ${ }^{[39]}$ and $\mathrm{Cu}-\mathrm{Fe}$

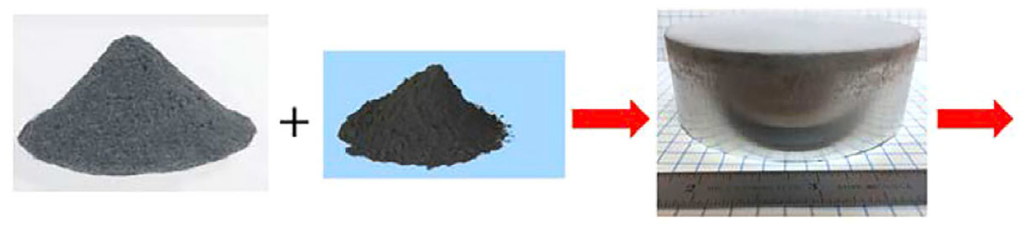

Al metal powders Ca metal powders Blended powder compact

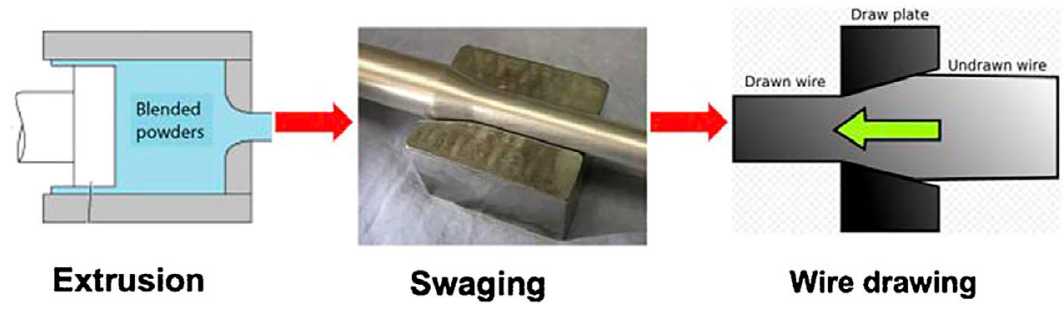

Figure 1. The production of a novel lightweight, high strength, high electrical conductivity Al matrix $\mathrm{Ca}$ nanofilamentary composite processed by power metallurgy and severe plastic deformation. ${ }^{[16,31,46]}$ composites studied by Hong et al. ${ }^{[40]} \mathrm{Cu}$ matrix based composites and $\mathrm{Al}$ matrix composites were extensively investigated by Russell et al. ${ }^{[41]}$ The composites, such as $\mathrm{Al}-\mathrm{Ti},{ }^{[42]}$ $\mathrm{Al}-\mathrm{Mg},{ }^{[43]}$ and $\mathrm{Al}-\mathrm{Sn},{ }^{[44]}$ are particularly important due to their lightweight, high strength and high electrical conductivity. Yu et al. ${ }^{[45]}$ studied a $\mathrm{Ti}_{2} \mathrm{AlC}$ reinforced magnesium composite processed by a hot extrusion method to align the $\mathrm{Ti}_{2} \mathrm{AlC}$ particles' basal planes with the extrusion direction. The ultimate compressive strengths of composite were $510 \mathrm{MPa}$ parallel to extrusion direction, whereas the corresponding value was $396 \mathrm{MPa}$ in an extruded magnesium alloy matrix phase.

Models for interfacial strength: Various "empirical interfacial strengthening" models have been proposed to explain the anomalously high strength of metal-metal composites underestimated by the rule of mixtures. Early developments of the models focused on empirical fitting in a qualitative way. Bevk et al. $^{[30]}$ first proposed a Hall-Petch relation between the anomalous strength of $\mathrm{Cu}-\mathrm{Nb}$ composites and the filament spacing. Despite the low volume fraction of $\mathrm{Nb}$ filaments, the $\mathrm{Cu}-\mathrm{Nb}$ composite can still achieve a strength close to that of copper whiskers. Spitzig et al. ${ }^{[47]}$ proposed a Hall-Petch barrier model that explains the strengthening effect as a result of the interface acting as a barrier to dislocation motion. The model assumed the Hall-Petch dependence of the composite strength on the filamentary spacing. Another model was proposed by Funkenbusch and Courtney ${ }^{[48]}$ as a work hardening model. This model attributed the extra strength above the rule of mixtures prediction to the "geometrically necessary dislocations" (GND) that are emitted from the interface to accommodate the strain incompatibility across the interphase boundary. These GNDs have the same strengthening effect as those of "statistically stored dislocations" (SSDs) obeying Taylor's hardening law. The density of GND is proportional to the strain incompatibility by a geometrical constant, which serves as a fitting parameter. Both of these models have limitations. The Hall-Petch barrier model cannot explain the high strength of cold-deformed two metallic phase materials relative to single phase material with similar filament spacing (i.e., grain size for single phase materials). The work-hardening model cannot explain the relatively low dislocation density in heavily deformed $\mathrm{Cu}-\mathrm{N}$ composite. ${ }^{[49]}$ However, the models may be complementary: one mechanism can be favored over the other depending on the amount of deformation processing and metal phases' crystal structure. Interface barrier effect appears to be the dominating strengthening mechanism at a large deformation true strain (usually larger than 10), at which interfaces begin to act as sinks for dislocations and hinder the generation of new dislocations from Frank-Read dislocation sources under the confinement of fine interphase spacing. ${ }^{[4]}$ The GNDs predominantly lead to extra strength when two different crystal structure metallic phases are deformed to a moderate true strain. Raabe et al. ${ }^{[50]}$ 
proposed a model using modified linear rule of mixture to simulate the strength of a general fcc matrix bcc filaments type composite. However, this model needs mathematical assumptions about the origin of the interface dominated Hall-Petch contribution. Without a description of the physical mechanism, the universality of the model is limited. All three models are semi-quantitative since they contain many empirical fitting parameters. Therefore, a new type of model was proposed to explain the anomalously high strength of metal-metal composites. These interface models can be classified as "physical mechanisms". Examples of such models will be presented next.

Strain gradient theories and models: Strain gradient theories are physics based theories that explain the size dependent deformation behavior of metallic materials at the micrometer scale. These models interpret the interfaces as the source of GNDs to accommodate strain incompatibility on a characteristic microstructural length scale. ${ }^{[51]}$ Generally, the "size effect" is used as a term to describe dependence of various properties of materials on the microstructure length scale (e.g., grain and secondary filament sizes). For example, Fleck et al. ${ }^{[52]}$ observed that the shear strength of thin copper wires increased more than threefold as the diameter of copper wire was reduced from 170 to $12 \mu \mathrm{m}$. Stolken and Evans ${ }^{[53]}$ observed a similar strengthening effect during bending tests as the $\mathrm{Ni}$ foil thickness reduced from 50 to $12.5 \mu \mathrm{m}$. De Guzmana et al. ${ }^{[54]}$ demonstrated that the microhardness of $\mathrm{Ni}$ and $\mathrm{Cu}$ samples increased as penetration depth decreased from 2000 to $200 \mathrm{~nm}$. Lloyd $^{[55]}$ observed a similar increase in the strength of $\mathrm{SiC}$ particle-reinforced composite as the particle diameter was reduced from 16 to $7.5 \mu \mathrm{m}$ under a $15 \%$ constant particle volume fraction. The size effect cannot be explained by the conventional plasticity theories as these do not include any intrinsic material length scale. ${ }^{[56]}$ To overcome the limitation, a material length scale was introduced in strain gradient plasticity theories to be compared with the characteristic microstructure dimension. ${ }^{[57]}$ The concept of strain gradient has also been adopted to explain the dependence of yield stress of polycrystalline materials on grain size-the Hall-Petch relation. Strain gradients in small dimension materials are produced by the GNDs to disrupt the crystalline lattice structure to improve the lattice structural continuity across the interface. ${ }^{[58]}$ A high density of GNDs will also strengthen crystals by Taylor's hardening law, similar to the role of statistically stored dislocations (SSDs). This demonstrates how the strain gradient affects the plasticity behavior of metals.

To explain the size dependent mechanical properties, various continuum models have been developed using the concept of strain gradient plasticity. Fleck and Hutchinson ${ }^{[52]}$ proposed a higher order couple stress theory to use an effective measure of a curvature tensor to represent strain gradients with rotation. Later, the stretch gradients were incorporated in the model. ${ }^{[59]}$ A higher order stress is defined as the work conjugate of strain gradient so that the Clausius-Duhem thermodynamic inequality can be satisfied. Many fitting parameters are needed in Fleck-Hutchison theories due to their phenomenological nature. Gao et al. ${ }^{[57]}$ proposed a mechanism based strain gradient theory to distinguish the microscale, at which the interactions of dislocations follow the Taylor's hardening law, from the mesoscale, where high order strain gradient plasticity is built upon. They used three deformation modes to derive an effective strain gradient measure linked with GNDs. Taylor's hardening law served as the founding principle to predict the linear relationship between the square of yield stress and strain gradient. This relationship was observed experimentally by Nix and Gao. ${ }^{[60]}$ This model has less adjustable parameters than FleckHutchison theory, and can predict the size effect experiments very well. Gao and Huang ${ }^{[61]}$ provided an alternative way to incorporate Taylor's hardening law into continuum theories without using the concept of high order stresses of mechanism based strain gradient theory. Their main idea was to obtain GNDs density by the nonlocal variables as a function of plastic strain by representing strain gradients as integrals of strains. The constitutive equations of this theory resemble those of conventional plasticity theory. Based on the concept of strain gradient plasticity, Tian et al. ${ }^{[62]}$ developed a dislocation density based strain gradient model for predicting the high strength in deformation processed metal-metal-composites. The idea to incorporate the strain gradient effect into modeling the yield stress of metal-metal-composites originated from the fact that the filamentary microstructure in the composite is in the submicron scale (as low as $20 \mathrm{~nm}$ ) and is obviously comparable with a typical material length scale - from a fraction of a micron to tens of microns. The fiber matrix interfaces can be a realistic source to generate the GNDs to create a strain gradient. They used a simple non-continuum formulation based on the assumption that effective strain gradient is directly proportional to the deformation true strain of severe plastic deformation and inversely proportional to the characteristic microstructure length (e.g., filament thickness) for uniaxial deformation mode. The average effect of different orientations of the slip systems is implemented as a material related parameter. For each metal phase, a modified yield stress is considered. This accounts for the work hardening effects from both statistically stored dislocations and GNDs whose densities can be determined by strain hardening curve and effective strain gradient, respectively. The yield strength of the composite would be the volumetric weighted average of modified yield strength of two metal phases. A comparison between this physical mechanism strengthening model and the previously empirical strengthening model developed by Funkenbusch and Courtney ${ }^{[48]}$ is demonstrated in Figure 2.

In addition to acting as the barrier and source of defects, the other interactions of interfaces with defects can be: sinks for defects due to absorption and annihilation and storage sites for defects. ${ }^{[28,63]}$ The strengthening models therefore can be developed based on the relation between strength and defects, where density evolution is controlled by interaction with interfaces. ${ }^{[64]}$ For example, the interaction of interface with radiation induced point defect, that is, a vacancy, can be described by a one-dimensional linear partial differential equation that governs the evolution of vacancy concentration.

Interface stability: Considering the important role of interphase boundaries, the interface stability can be critical to the interface 


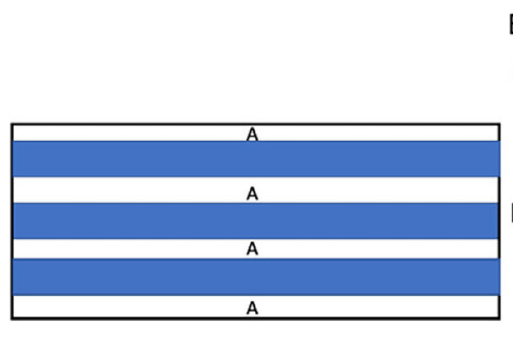

Empirical dislocation based model:

$$
\frac{d \rho_{A_{-} \text {tot }}}{d \varepsilon}=C_{1} \frac{\sqrt{\rho_{A_{-} t o t}}-C_{2} \rho_{A_{-} t o t}}{\frac{d \rho_{A_{-}} S S D s}{d \varepsilon}} \frac{\frac{P_{A} K}{V_{A_{A} D_{A}}}}{\frac{d \rho_{A_{-} G N D S}}{d \varepsilon}}
$$

Physical mechanism dislocation based model

$$
\rho_{A_{-} t o t}=\underbrace{\left[\frac{\left(\sigma_{Y}-\sigma_{0}\right) f(\varepsilon)}{m \alpha G b}\right]^{2}}_{\rho_{A_{-} S S D S}}+\underbrace{\frac{\frac{\eta}{b}}{1}}_{\rho_{A_{-} G N D S}}
$$

Figure 2. A comparison between empirical dislocation based strengthening model developed by Funkenbusch and Courtney ${ }^{[48]}$ and physical mechanism dislocation based strengthening model developed by Tian et al. ${ }^{[62]}$ for metal-metal composites (in the left figure, unshaded region is phase $A$ and shaded region is phase B). Both models are dislocation density based models building upon Taylor's hardening law, where the total dislocation density was assumed to be a simple summation of two types of dislocations, that is, (SSDs) and (GNDs). The empirical model has many fitting parameters to be determined from the experimental results, while the physical mechanism model has much fewer physical parameters that can be justified from physical principles. The final strength of metal-metal composites in both models is the rule of mixtures of modified strength of each phase.

properties. For example, in $\mathrm{Cu}-\mathrm{Nb}$ composite, the $\mathrm{Nb}$ filaments tend to break up into segments under elevated temperature. ${ }^{[65]}$ This spheroidization phenomena decreases the interface area and weakens the interfaces' barrier effect to lattice dislocation motion. The stability and evolution of interfaces have been studied in detail for two metal phase composites under elevated temperature $^{[66]}$ and radiation. ${ }^{[67]}$ Tian et al. ${ }^{[66]}$ used phase field approach to study the interfacial morphological change at elevated temperature. Their results suggested that the stability of interface obeys Rayleigh's instability criterion. Rayleigh's criteria were originally derived from the jets of fluid, ${ }^{[68]}$ that is, the interface will be stable when the periodic interface perturbation wavelength is less than the initial rod circumference. Otherwise, it is unstable against these interface perturbations and evolves into segments (i.e., when the perturbation wavelength is larger than initial rod circumference). This interface stability criterion is demonstrated in Figure 3. This model was investigated by Tian et al. using a phase field approach. ${ }^{[66]}$ Figure $3 a-c$ demonstrate the effect of interfacial perturbation wavelength $\lambda$ on the interfacial stability and morphological evolution. The left part of each figure is the initial composition distribution with the only difference being the interfacial perturbation wavelength $\lambda$. The right part of each figure is the spatial composition

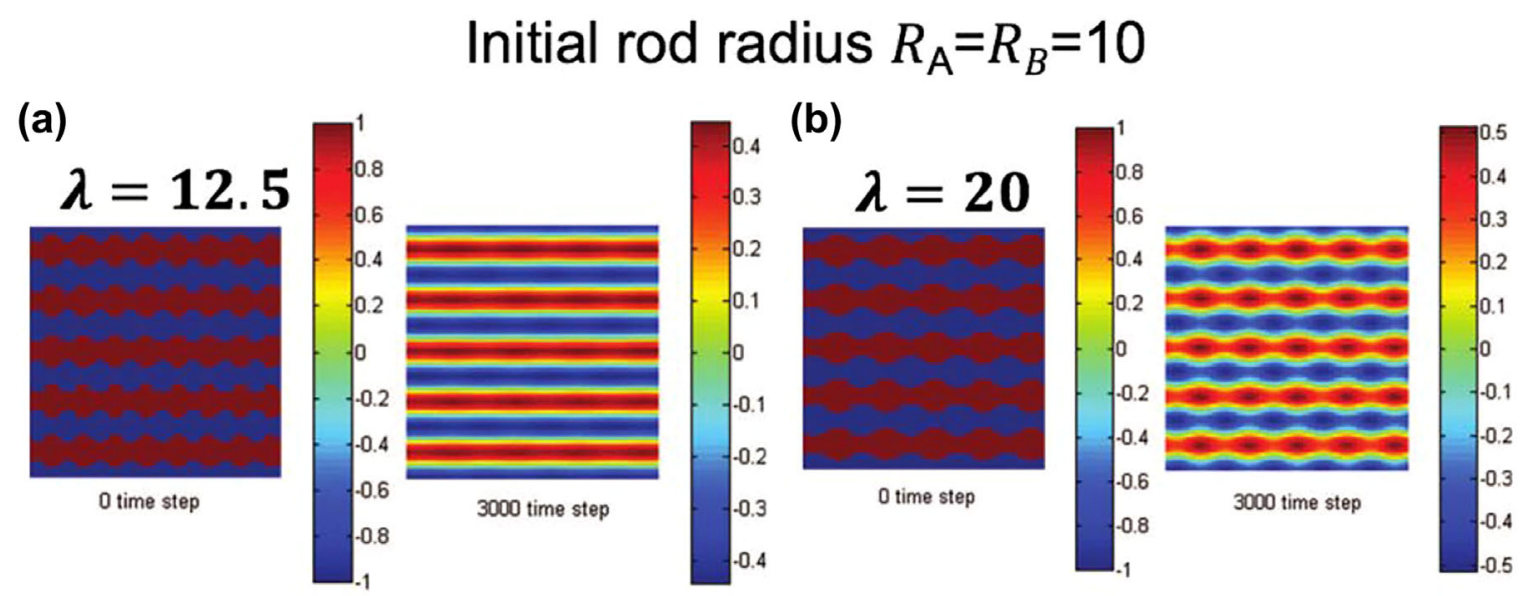

(c)

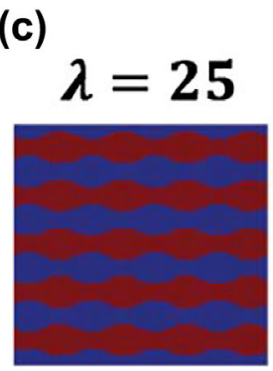

0 time step

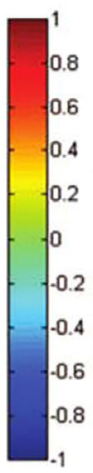

(b)

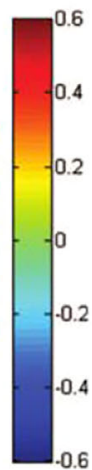

Figure 3. The spatial and temporal evolution of composition in a two-phase composite system was investigated by Tian et al. using phase field approach. ${ }^{[6]}$ 
distribution after 3000 time steps with each time step $4 \times 10^{-3}$. It is clear that the two phase composite with perturbation wavelength 12.5 in (a) is stable against the interface perturbation while the composite with perturbation wavelength 25 in (c) is unstable against interface perturbation and break up into segments. The numerical simulations were conducted in a 100 by 100 two dimensional square lattice (grid size 1) using the finite difference method. In all figures, the initial unperturbed rod radius $R_{\mathrm{A}}$ and $R_{\mathrm{B}}$ are both 10 so that the circumference of unperturbed rod for each phase in two dimensional simulations is 20 and the volume fraction of each phase is $50 \%$. The red phase A and blue phase B are separated by a single harmonic interface, whose perturbation amplitude $\delta=2$. The color bars show the magnitude of composition with 1 representing phase $A$ and -1 representing phase $B$.

Zhang et al. ${ }^{[67]}$ studied the stability of $\mathrm{Cu}-\mathrm{Nb}$ interface under radiation and suggested that the interface is morphologically stable when its individual layer thickness is between 2 and $4 \mathrm{~nm}$. They used molecular dynamics to generate the initial concentration mapping for phase field simulations. Their results suggest that most of the interfaces survived and were stable during radiation except one $\mathrm{Nb}$ layer pinched off.

Misfit dislocations and coherency at the interface: Interfaces usually contain internal structures comprised of misfit dislocations, which in turn control interface properties. When two crystalline solids form an interface, the crystalline lattices of two phases will have to accommodate two forms of distinct interface structures parallel to the interface. The extent of the difference between their lattice parameters determines the misfit strain which, in turn, can be accommodated in different ways. When the misfit strain between two crystalline phases is small (usually less than $5 \%$ ), the interphase boundaries form coherent interfaces that are perfectly aligned atomic planes. The mechanism involves any elastic straining of the atomic planes for both crystal lattices to either increase or decrease the separation between atomic planes by a small amount from their equilibrium positions. In this case, the resultant lattice planes of coherent interfaces are continuous across two phases. Coherent interfaces may form between two phases with distinctive crystal structures, as long as the lattice parameters of atomic planes perpendicular to interfaces are sufficiently close. When the misfit strain is intermediate, the resultant interface is "semi-coherent". The interface in this case usually comprises an ordered array of misfit dislocations separating coherent regions. The lattice planes of coherent regions are continuous while some lattice planes are not continuous due to the extra misfit dislocations. This type of interface is considered very important since it occurs frequently in bimetallic composite. ${ }^{[69]}$ The misfit dislocation density determines the spacing between misfit dislocations, which acts as forest obstacles for the plasticity-carrying dislocations to transmit through. The misfit dislocation array models are invalid when the misfit dislocation spacing is small enough to cause the dislocation core overlap. Yao et al. ${ }^{[70]}$ proposed a model to treat the interfacial misfit dislocation array by introducing PeierlsNabarro's ideas. They derived a simple yet effective analytical solution as an extension of Peierls-Nabarro's model by incorporating the core structure and energy of misfit dislocations. They found the condition at which the interface structure can be described by an ordered array of singular Volterra dislocations. When the misfit strain exceeds 25\%, the lattice planes fail to maintain continuity across the interfaces completely. This misfit strain is too large to be accommodated by the misfit dislocations that require at least some coherency in lattice planes. The interface energy generally increases when the level of coherency decreases.

Coherency can be considered as a measure of the ability to maintain the crystal structure of each phase when the phases have to "glue" together to form an interface. Vattre et al. ${ }^{[69 b]}$ developed a computational method to design interfaces with desired misfit dislocation patterns. This was accomplished by tailoring the crystal structure and composition at the interface. They used a mesoscale reduced order model built on anisotropic elasticity theory, instead of an expensive atomistic simulation, to predict the misfit dislocations pattern. The model determines the interface properties (e.g., point defect mobility and shearing resistance) with an accuracy comparable to atomistic simulation predictions. In this "reduced order model", they used less than 15 variables to define the misfit dislocations in the design space. To solve the same problem using an atomistic simulation, one would need millions of variables to represent the atomic positions.

\subsubsection{Homophase Interface in a Metal-Metal-Composite}

Homophase interface and contact bond between grain boundaries separating the crystals with different orientation in a single phase polycrystalline material are of great interest to a wide range of researchers due to their potentials in manufacturing of advanced materials. An interesting example is the homophase interface in a nano-crystalline material; as the material exhibits unusual properties due to its grain structure. Depending on the grain size spectrum in the composite, its role in the bonding strength of material can be defined; the classical Hall-Petch model does not apply to the entire spectrum.

Microscale polycrystalline: The homophase interface between microscale polycrystalline, that is, grain boundaries, has a direct impact on the strength of a homophase material that can be predicted by a Hall-Petch model. ${ }^{[71]}$ The primary role of grain boundary in this model is to resist the lattice dislocation motion. This usually happens when the grain size is above $1 \mu \mathrm{m}$ so that the lattice dislocation motion inside the grain interior is the carrier of plastic deformation. When the grain size is between $1 \mu \mathrm{m}$ and $1 \mathrm{~nm}$, the Hall-Petch relation holds approximately, but differs from the classical -0.5 exponent to a value close to zero. However, the Hall-Petch model becomes invalid when the grain size reduces further to the nanoscale regime. ${ }^{[71]}$ For grain sizes below $100 \mathrm{~nm}$, the material is classified as nano-crystalline. ${ }^{[71,72]}$ When the grain size decreases below a critical size (e.g., around ten nanometers), the grain boundaries become the dominating phase, and the grain boundary mediated deformation mechanism is responsible for the plastic deformation. In this regime, the dependence of strength on grain size becomes unusual, that is, the strength decreases with reducing grain size. This behavior 
is generally known as inverse Hall-Petch relation. ${ }^{[73]}$ This transition from a dislocation mediated to a grain boundary mediated deformation mechanism leads to a maximum strength at a critical grain size that strongly depends on the stacking fault energy of fcc metals, the elastic properties, and the applied stress, as demonstrated in Figure $4 .^{[74]}$ The properties of nanocrystalline materials are largely controlled by their grain size and the interaction of their defects. ${ }^{[75]}$

Since the strength of microscale polycrystalline materials can be well described by the Hall-Petch model, we will focus more on the strengthening models of nano-crystalline materials due to their unconventional properties, including "grain boundary mediated plastic deformation mechanism".

Nanoscale polycrystalline: Various theoretical models have been developed to predict the strength in nano-crystalline materials based on their distinctive nanoscale grain size. Two common models are those based on physical mechanisms of plastic deformation and their recent developments are based on the concept of the rule of mixtures.

The rule of mixtures: This types of model takes the nanocrystalline material as a multi-phase composite with grain interiors and grain boundaries as the primary constituent phases. This approach predicts mechanical properties of the nano-crystalline materials using averaged mechanical properties and volume fractions of the constituent phases. The predicted strength of nano-crystalline materials takes the volumetric weighted sum of strength for each phase component. The downside of this model is the complexity of extracting the

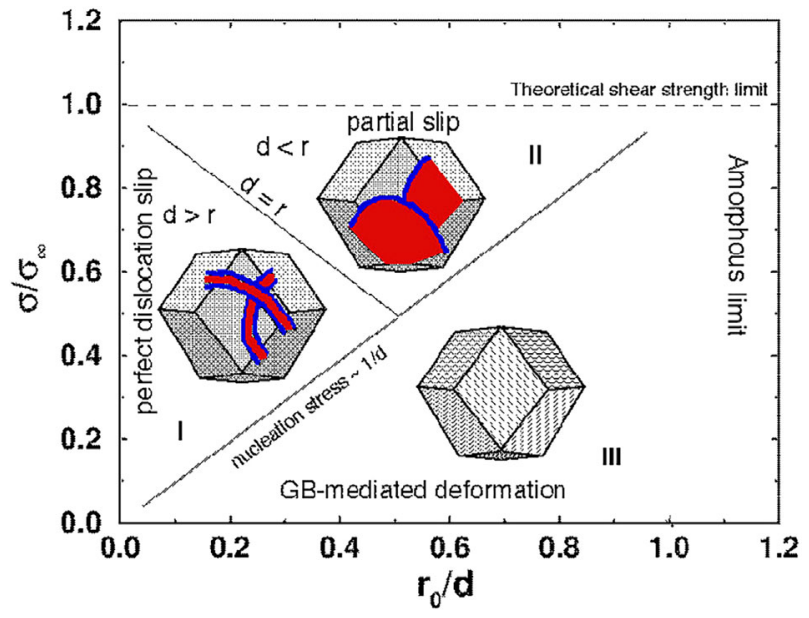

Figure 4. An illustration of the deformation mechanism map of nanocrystalline metals proposed by Yamakov et al. ${ }^{[7]}$ The $x$ axis is the inverse of grain size and $y$ axis is the applied stress. This map shows three distinctive regions for deformation behavior of nano-crystalline fcc metals, demonstrating a transition of deformation mechanism from dislocation mediated deformation to grain boundary mediated deformation. The normalization parameters depend on the material parameters, that is, stacking fault energy and the elastic properties. (Reproduced with permission. ${ }^{[74]}$ 2003, Springer Nature). mechanical properties of grain boundary phase. Kock et al. ${ }^{[76]}$ first proposed to treat grain boundary layers of thickness $t$ as a separate phase beside grain interior bulk phase. They obtained an inverse relation between yield strength of a polycrystalline solid and grain size under the assumption that strength of grain boundary and grain interior are independent of the grain size. Based on this idea, Gryaznov et al. ${ }^{[77]}$ extended Kocks' work to obtain a generalized empirical model resembling the Hall-Petch law at large grain size and predicting the existence of a critical grain size below which the Hall-Petch relation breaks down. In their model, the critical grain size at which deviation from the Hall-Petch law begins was predicted by the interface atomic density. Similar studies ${ }^{[78]}$ based on the rule of mixtures were performed to treat the grain boundary phase as an amorphous counterpart with similar chemical composition. This is since the atoms in the grain boundary of nano-crystalline materials are in a totally disordered state that resembles an amorphous material. Wang et al. ${ }^{[79]}$ proposed a composite model with the grain interior, grain boundaries, their triple junctions and quadruple nodes as the constituent phases. Their model can explain the grain size dependent on the yield stress for each constituent phase. They also argued that the grain size dependence of creep rate is higher for triple line diffusion than that of the bulk and grain boundary diffusion. The aforementioned rule of mixtures based models overlook the role of physical mechanisms of plastic deformation.

Physical mechanism based strengthening models: This type of model focuses on the evolution of defects and grain boundary structures in terms of different physical mechanisms of plastic deformation, such as crystalline dislocation motion, grain boundary sliding, and diffusion based mechanisms. ${ }^{[80]}$ Various deformation mechanisms can simultaneously operate inside nano-crystalline materials. The model assumes that these mechanisms are responsible for the strength of the deformed composite. The effect of nanoscale grain size on the strength of nano-crystalline materials is reflected by the competition between various deformation mechanisms with the grain size, or the co-operation of multiple deformation mechanisms due to a grain size distribution. This approach allows the simultaneous operation of different deformation mechanisms in various local areas of nano-crystalline material with different grain size distributions to estimate the averaged mechanical properties of nano-crystalline materials.

Hahn et al. ${ }^{[81]}$ proposed a strengthening model based on the grain boundary sliding mechanism. The model assumes a negative inverse square root dependence of hardness on grain size. Hahn et al. ${ }^{[73 b]}$ also proposed a model to describe the nanocrystalline materials' yield strength based on the grain boundary sliding mechanism. They assumed that the work needed to create the extra grain boundaries is equal to the work done by the external force which is responsible for the grain boundary sliding. Gutkin et al. ${ }^{[82]}$ attributed the strengthening of nanocrystalline materials to the role of triple junctions of grain boundaries acting as obstacles for grain boundary sliding. They assumed that the dependence of the yield stress on grain size and triple junction angles is determined by a competition between dislocation slip and grain boundary sliding. They also 
assumed that a competition exists between conventional dislocation slip and Coble creep in a heat treated nano-crystalline material. They proposed a distribution for the grain sizes and triple junction angles that mimics those in the real specimens. Figure 5 illustrates the difference in treating grain boundary structure of nanocrystalline materials by the previous rule of mixtures approach and the current physical mechanism based approach.

The models discussed above do not provide a universal relation between strength and grain size over a wide range of grain sizes. Masumura et al. ${ }^{[83]}$ proposed a model and developed an analytical expression for the yield shearing strength, $\tau$, as a function of the inverse square root of the grain diameter, $d$, in a simple and approximate manner. This enables comparison of the model's predictions with the corresponding experimental data over a wide range of grain sizes. There are also a number of models which incorporate both "the rule of mixture" and "the physical mechanism based" approaches. Kim et al. ${ }^{[84]}$ proposed a rule of mixtures model that takes the plasticity and deformation mechanism into consideration. They used the unified viscoplastic constitutive relations to represent the mechanical properties of the crystalline phase by incorporating dislocation density evolution and diffusion creep. The deformation mechanism for the grain-boundary phase was modelled as a diffusional flow through the grain boundary. This polycrystalline material model can account for both the grain size dependence of the overall plastic deformation and its rate effects. Li et al. ${ }^{[85]}$ developed a quantized crystal plasticity model that incorporates the grain-size effect by discrete jump of grain averaged plastic strain. The jump magnitude is inversely proportional to the grain size due to the stochastic nature of dislocation nucleation at grain boundaries.

Given the limitations of the micro-mechanical models and the large number of parameters involved, further experiments and observations are essential to develop more meaningful theories in support of the universal models, which eventually can reliably

(a)

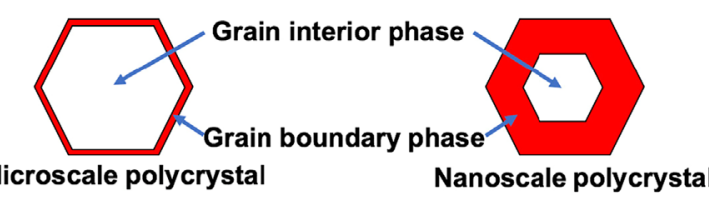

(b)

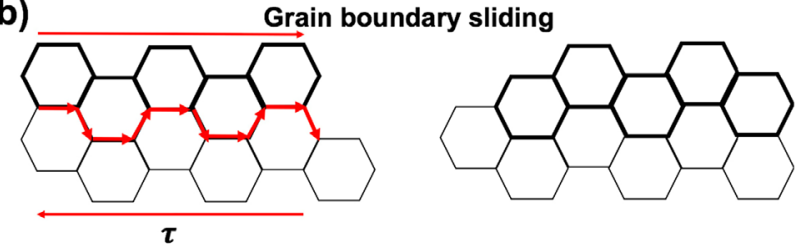

Figure 5. A schematic to compare the difference in treating grain boundary structure in nano-crystalline materials by the rule of mixtures approach and physical mechanism based approach. The rule of mixtures approach demonstrated in a) treated the grain boundary as a separate phase resembling grain interior, while the physical mechanism based approach in b) take the sliding of grain boundary as the physical mechanism for plastic deformation. predict the bonding strength. The "micro-mechanical" analytical models are reviewed next.

\subsection{Micro-Mechanical Approach}

Increasing the length scale, one might consider a bulk approach to describe the bonding. This is when an intermediate length scale, such as particle size, is considered to describe the hybrid metal bonding. An example of this is the composites fabricated by cold powder compaction. Such metal-composites belong to a larger category known as architectured metal-composites. A strength model for this case depends on several other parameters including the geometry and sizes of "deformed particles" (or splats). Due to complexity of their geometry and inaccessibility of the interfaces, modeling and characterization of such metal-composites are not simple and typically rely on average properties.

\subsubsection{Homophase Interface between Compacted Powders}

The homophase interface between powder particles is an interesting example of the contact bond between powder particles after they have been deformed and compacted. The bonding strength of this type of interface is generally attributed to the compaction pressure, the green density and the interparticle contact area. ${ }^{[86]}$ The formation of metallurgical/chemical bonding between particles is critical to the strength of green powder compact, which is affected by the properties of the powders (e.g., compact density, particle size and shape, internal pores in the particles, oxidation, and powder material properties) and the processing conditions (e.g., compaction pressure, temperature, dwell time, friction condition like lubrication, and the binding additives). ${ }^{[86 c]}$ Anderson et al. ${ }^{[87]}$ investigated the effect of oxides and/or hydroxide films on the typical powder surfaces on the inter-particle bonding, densification behavior and sintering ability. They studied how the surface oxide coating, consolidation and sintering behavior can benefit from an advanced powder production technique called gas atomization reaction synthesis (GARS). An obvious reduction in the surface oxide/hydroxide film thickness and the level of absorbed moisture were observed in the powders produced by the GARS process, which favor the sintering response. Lefebvre et al. ${ }^{[88]}$ verified that the surface modification of iron powder can strongly influence the green strength of the powder compact.

\subsubsection{Contact Bond Formation Mechanisms}

Different hypotheses and models exist to explain the contact bond mechanisms of metallic materials. Melting is generally excluded in such models due to the complexity of physicochemical processes in the contact area, such as recrystallization, diffusion, dislocations, and deformation. ${ }^{[86 a]}$ Three stages are generally proposed for the formation of chemical bonding between contacted powders, that is, formation of physical contact at which the van der Waals forces are operative, formation of active nuclei at the contact interface and formation of strong 
chemical bonds at contact area for the whole volume. ${ }^{86 a]}$ Sintering of green compact is usually necessary to enhance the bond strength between powders and to reduce the porosity before the compact can be handled by other processing methods. The thermodynamics of densification due to sintering has been studied by Kellett et al., ${ }^{[89]}$ who found the existence of a critical pore coordination number, below which the pores are thermodynamically unstable to sinter, so that subsequent pore shrinkage and densification occurs. Castro et al. ${ }^{[90]}$ investigated the effect of dopants on interfacial energy and the subsequent sintering response. Hirata et al. established the necessary thermodynamic condition to achieve the full densification of sintered powder compact. ${ }^{[91]}$

\subsubsection{Cold Compactions Process}

Understanding the mechanisms that occur during cold compaction is extremely important to correlate the compaction pressure, density, and strength. A cold compaction process can generally be divided into three distinct stages. In the first stage, particles restack and slide past each other without any deformation. ${ }^{[92]}$ The second stage involves both elastic and plastic deformation to form necks between the particles to increase their contact area. This stage results in welding of powders and an increase in the compact strength. The third stage involves the bulk compression of compacted powder. A linear relation between compressive strength and the density of green compact has been found in the latter two stages. In addition, the particle fracture mechanism could also contribute to the densification and compaction behavior under a large compaction pressure. ${ }^{[93]}$ It was found that a combined use of pressure and shear deformation is beneficial to the formation of splat-shaped deformed particles and eventually contributes to an improvement in their mechanical bonding. ${ }^{[94]}$

\subsubsection{Models of Green Strength to Describe the Powder Compacts}

There is a lack of general quantitative theories to formulate a universal relationship between green compact strength and various parameters affecting the bonding strength. This can be explained by the empirical nature of the existing correlations whose parameters typically cover only a narrow spectrum of the entire feasible range. ${ }^{[86 c]}$ The complex problem becomes more challenging when the interactions between the parameters and the key process invariances in the experiments are considered.

Various models have been developed to correlate the green strength for powder compacts to the powder properties and processing parameters. Bal'shin first proposed a simple linear relationship between the ultimate strength of green compact and the forming pressure based on experimental study of lead powders. ${ }^{[95]}$ Radchenko studied the strength of green compact made up of iron, nickel and its alloys, copper, tin, and zinc powders and suggested a dependence of green compact strength on compact porosity based on Bal'shin equation assuming a linear relationship with powder's relative bulk density. ${ }^{[86 \mathrm{a}]}$ Moon et al. ${ }^{[86 \mathrm{~d}]}$ reported an increase in the strength of $\mathrm{Cu}$ compact with increasing green density and compacting pressure. They attributed this phenomenon to the directly proportional increase of the contact area between powder particles. Farley et al. ${ }^{[96]}$ later incorporated the concept of the contact cross-section to suggest a linear dependence of the green compact's ultimate strength in compression on the fraction of total pressed cross-section that was in contact. Easterling et al. ${ }^{[97]}$ proposed that the driving force to keep the particles together, that is, adhesion, comes from the reduction in energy when forming a grain boundary from two surfaces in the contact zone. They further concluded that the bonding strength was directly proportional to the adhesion, and inversely proportional to the radius of metallic particle. ${ }^{[97]}$ They also proposed a formula for the stresses due to interatomic bonding at the interface between two equal size spherical metallic particles. Bortzmeyer ${ }^{[98]}$ derived a similar inverse relation between the particle size and the tensile strength of ceramic compact with a random packing of equal size powders. Nikolakakis et al. ${ }^{[99]}$ proposed a model to predict the tensile strength of green compact as a function of particle shape, particle diameter, and packing fraction for both fine powders (less than $10 \mu \mathrm{m})$ and coarse powders $(18-28 \mu \mathrm{m})$. Golubev et al. ${ }^{[100]}$ proposed a green strength model for lithium hydride powder compact that predicted a negative logarithm dependence on particle size and linear dependence on the compact density. Another type of model relating green strength to porosity and/or the features of pores was proposed by Ryshkewitch. ${ }^{[101]}$ Khoddam et al. ${ }^{[94]}$ developed a dimensional analysis to establish a correlation in the compacted samples which was calibrated using the strength measurements obtained using dedicated micro-shear punch tests. Though these models are applicable to their material systems and experimental settings, they cannot be generalized as a universal formula to estimate the green strength of powder compacts. This indicates the need for future research in this area to investigate this relationship for various powder compaction processes.

\subsubsection{Presence of an Intermediate Layer}

Presence of an "intermediate layer" or a "medium" between the constituents is another common feature in many such metalcomposites. The intermediate layer can be intentionally placed between the constituents, via a dedicated manufacturing process, to provide a given functionality for the composite. Examples of this case include the application of a layer of glue, foam or insulator. Alternatively, the intermediate layer can be produced unintentionally when it can weaken the bonding strength of the composite. Examples of the latter include the presence of rust, oxide, and chemical residuals between the constituents. In either case, the intermediate layer dictates the bonding strength of the composite structure.

There are many cases in the literature describing how the strength of individual components is evaluated or changed due to the processing conditions. However, it should be noted that the bonding strength can be seriously limited in the presence of an intermediate layer and become the weakest zone in the 
structure. If this is the case, the failure of the structure occurs at the interface before each component reaches its yield limit.

\section{Fabrication and Joining Methods}

Various joining processes are used to join similar and dissimilar materials. A few examples, which are commonly used to produce metal-composites, are briefly discussed in this review.

\subsection{Diffusion Based Welding (DBW) Methods}

Metallic materials are commonly joined by Oxy-fuel gas arc welding, solid state welding, brazing, and soldering. When joining metals and non-metals, a wider range of processes are available. Solid state welding processes can be performed using the processing methods of forge, inertia friction, friction stirring, diffusion, high speed impact (e.g., magnetic pulse, explosive, laser shock impulse, vaporizing foil actuator) and ultrasonic means. Diffusion based welding (DBW) process is performed at elevated temperatures. The diffusion bonding process is mainly suitable for joining dissimilar metals. It is particularly suitable for joining highly reactive metals such as titanium, beryllium, zirconium and other composite metals by diffusion bonding. ${ }^{[102]}$ In recent years, researchers have developed many new efficient DBW methods to join dissimilar materials and to obtain materials with a specific combination of properties. Particular attention to diffusion based joining is given in this review since interface diffusion can commonly occur during metal joining. Typically, interface diffusion requires a high temperature (50-80\% of melting temperature), pressure and sufficient processing time. However, a significant increase of pressure or any other input, such as strain rate, may significantly reduce the requirement in another area, such as temperature or processing time. ${ }^{[103]}$ Another key development in diffusion based joining is "additive manufacturing" which will be reviewed later in the following sections.

\subsection{Metal Cladding Processes}

Deposit of a material on another material is generally known as coating when a depositing material is in the form of liquid or gas. The term "cladding" is used when the deposition is carried out in a solid form. Based on this classification, roll bonding, explosive welding and extrusion processes are considered as cladding processes. ${ }^{[104]}$ A cladding process laminates a layer over the parent material. This adds another new functionality to the resulting metal-composite. Examples of this include corrosion resistance, wear resistance, electrical conductivity, thermal conductivity and improved appearance.

Chen et al. ${ }^{[105]}$ investigated a laser cladding of an alloy steel to improve the fatigue strength. They found that the process increased the fatigue life of the parent metal by 2-5 times compared with un-cladded specimens. However, they found that defects such as voids in the cladding layer can affect the fatigue strength and cause large variations in the fatigue life of manufactured parts. ${ }^{[105]}$ They reported that the specimens without large defects were notably stronger.

\subsection{Joining by Bulk Forming Processes}

Several bulk metal forming operations have been adopted or modified to perform "plastic deformation induced joining", also known as deformation-joining of metal-metal-composites (DMMCs). ${ }^{[25]}$ These operations mainly involve a significant deformation in metals whose initial form is bulk. The wide spectrum ranges from traditional bulk operations to their modified versions. Typical examples of the former are forging, rolling, drawing, and extrusion.

\subsection{Extrusion Based Bonding}

One of the early attempts to bond $\mathrm{Cu}-\mathrm{Al}$ by hydrostatic extrusion process was that invented by Nilsson in 1973. ${ }^{[106]}$ The process proved to be successful with other base metals. ${ }^{[107]}$ This study aimed to fabricate a hard core with a soft clad material as an alternative coating method. It was expected that the hard core would not undergo a significant shape change or deformation in the project. However, various core failures with different extrusion ratios were noticed. Osakada et al derived a mathematical model to describe the failure modes, such as necking under tension at the exit or irregular non-steady deformation of the core material. ${ }^{[107]}$ They assumed a proportional ratio of material flow behavior when deriving their mathematical models. They suggested the same extrusion ratio and reduction for both core and clad. ${ }^{[107]}$ Ahmed ${ }^{[108]}$ investigated parameters of copper clad aluminum for some fabrication processes such as die design. The parameters included extrusion ratio, extrusion velocity, extrusion pressure, and percentage of copper for an axisymmetric hydrostatic extrusion. Ahmed developed analytical solutions to calculate the required hydrostatic pressure at various extrusion ratios for aluminum hybrid rods with $15 \%$ copper cladding. ${ }^{[108]}$

Sliwa examined plastic flow behavior for a co-extrusion of two metals for a number of scenarios. ${ }^{[109]}$ In the study, the researcher quantified the total plastic strain of the composite and the individual plastic strain of each material. In order to understand the plastic flow, micro structural properties of the co-extruded materials were investigated. ${ }^{[109]}$ This work indicated that the material flow of a composite rod depends on individual deduction ratios of the core and clad. Sliwa concluded that use of a global extrusion ratio for the deduction ratios of the core and clad materials was not suiTable Sliwa also studied the plastic zone and dead zone in a simultaneous extrusion process for nonproportional and proportional flow, and suggested that the extrusion ratios depend on the interfacial bonding between the materials. ${ }^{[110]}$ However, the research did not include the role of the core-clad extrusion ratios on the formation of bimetallic bonding.

An industrial scale experiment was conducted to fabricate $\mathrm{Cu}$-clad $\mathrm{Al}$ composite samples at $320^{\circ} \mathrm{C}$ using a horizontal hydrostatic extruder with $1.5 \mathrm{MN}$ capacity. ${ }^{[111]}$ The process parameters including stroke, pressure and different extrusion die angles $\left(30^{\circ}, 45^{\circ}\right.$, and $\left.60^{\circ}\right)$ for three different extrusion ratios $\left(8.5,19\right.$, and 49) were investigated. ${ }^{[11]}$ They also analyzed the bond using Scanning Electron Microscopy (SEM) and Energydispersive X-ray spectroscopy (EDX). They recommended the 
parameters of an extrusion ratio equal to 19 with a die angle of $45^{\circ}$ to achieve a good quality bonding.

The high purity $(99.99 \%)$ Al powders with particle size between 45 and $106 \mu \mathrm{m}$ were produced by the Ames Laboratory unique gas atomization reaction synthesis (GARS) process. These coarse Al powders with a wide particle size distribution are very beneficial for making high quality green compacts with high green density during the powder compaction process due to the substantially reduced surface oxides and hydroxides, and the tendency to fill in more gaps. ${ }^{[87]}$ The high purity $(99.5 \%) \mathrm{Ca}$ metal powders $(106-212 \mu \mathrm{m})$ were produced by a unique centrifugal atomization system with rotating quench bath developed at Ames Laboratory. ${ }^{[34]}$ The powders (80 vol\%, $157 \mathrm{~g}$ Al powders and 20 vol\%, $22.4 \mathrm{~g}$ Ca powders) were mixed in a TURBULA Shaker-Mixer and then die pressed into cylindrical powder compacts with a relative density of $65 \%$ under 40.6 MPa pressure. This compaction pressure and green density matched the compressibility curve for gas atomized $\mathrm{Al}$ powders. ${ }^{[112]}$ These cylindrical powder compacts were then loaded into a pure Al (1100-H14) extrusion can and degassed under vacuum $\left(2.7 \times 10^{-5} \mathrm{~Pa}\right)$ to eliminate gases and moisture adsorbed on the powder surfaces before backfilling with Ar gas. The end cap of the extrusion can was then welded by the electron beam. The welded extrusion cans were then extruded under $285^{\circ} \mathrm{C}$ at an extrusion force $1.9 \mathrm{MN}$, an extrusion ratio 10.6 , a ram speed $1.5 \mathrm{~mm} \mathrm{~s}^{-1}$ to convert spherical Ca metal powders to co-axial filaments. The as-extruded $\mathrm{Al} / \mathrm{Ca}$ composite rods were covered by a layer of pure $\mathrm{Al}$ which originated from the pure $\mathrm{Al}$ extrusion can. This surface Al layer was then removed with a lathe. Further deformation processes at room temperature were then conducted by swaging and wire drawing to achieve the maximum deformation true strain 12.9 , which should produce Ca filaments with average diameter around $200 \mathrm{~nm}$ that would strengthen the composite to sufficient strength while minimizing their detrimental effect to electrical conductivity due to interface scattering. ${ }^{[16,35]}$

An interesting sub-class of the bulk forming processes is "architectured joining" which has been regarded as a paradigm change in materials design. To demonstrate some of the recent developments in modeling and characterization of the metalcomposite joints, a few architectured joining techniques will be reviewed next.

\subsection{Architectured Joining}

Some modern processing techniques such as Severe Plastic Deformation (SPD) processes, typically used to process single materials, have recently been applied to fabricate "architectured hybrid materials". In the last decade, SPD processes became an attractive method in material processing, resulting in improved specific characteristics. This enables the manufacture of a new class of hybrid materials. Architectured joining was introduced by Bouaziz et al. ${ }^{[113]}$ as a paradigm change in fabrication of metal-composites. The technique employs both "plastic deformation induced joining" and "severe plastic deformation" (SPD) processes (e.g., ${ }^{[114-117]}$ ). This justifies the need to study "process deformation" as a parameter to model the bond-strength for the architectured joining processes.
SPD processes have the potential to produce bulk ultra-fine grained materials. ${ }^{[118]}$ The combined bulk "grain refining" and "inner architecturing" of a metal- composite introduces a new avenue in materials design. ${ }^{[113,119-121]}$ Formation of the ultrafine-grained micro-structure in the metal-composite contributes to the ultra-high strength of the fabricated material (i.e., "architectured hybrid material"). Mechanisms of strengthening and property changes during SPD processing have been studied extensively. However, the parameters and phenomena that govern the bonding strength of an "architectured metalcomposite" are less known and need further investigation. A brief review of some selected SPD processes, that have been used recently in the architectured joining, will be presented next.

\subsubsection{SPD Processes}

Severe Plastic Deformation (SPD) processes mainly induce high shear deformation in their sample at a relatively low temperature under a large hydrostatic pressure. ${ }^{[118,122]}$ The deformation is imposed in a near zero shape change fashion. SPD processes are considered mainly to enhance the material property using various strengthening mechanisms. In general, SPD processes increase the number of dislocations to accommodate the strain energy due to the plastic deformation. ${ }^{[123]}$ The dislocation density in an annealed metal (without stored residual stresses) is about $10^{4}$ to $10^{6}$ dislocations per square millimeter while a metal processed using an SPD process contains about $10^{10}$ dislocations per square millimeter. ${ }^{[123]}$

According to Valiev et al., ${ }^{[122 e]}$ a "true" UFG can be defined as having a size of less than $1 \mu \mathrm{m}$ and more than $70 \%$ high angle grain boundaries with a disorientation angle of greater than $15^{\circ}$. SPD processes can produce submicron grains (grains $<1 \mu \mathrm{m})$ at temperatures lower than $0.4 T_{\mathrm{m}}$ and nano-crystalline grains at temperatures below $0.2 T_{\mathrm{m}} \cdot{ }^{[124]}$ However, a large hydrostatic pressure is needed to successfully produce nanocrystalline grains in most metals when the operating temperature is below $0.2 T_{\mathrm{m}} \cdot{ }^{[124]}$

Examples of SPD techniques include high pressure torsion (HPT) and equal channel angle extrusion (ECAE) ${ }^{[125]}$ multidirectional forging (MDF), sandglass extrusion (SE), repetitive corrugation and straightening (RCS), twist extrusion (TE), ${ }^{[126]}$ constrained groove pressing (CGP), accumulated roll-bonding (ARB), additive roll bonding (ARB), and forward or direct extrusion (FE/DE). The most commonly used SPD techniques are HPT and ECAE, which are the earliest SPD techniques invented during the 19th century. HPT and ECAE were developed by Bridgman ${ }^{[127]}$ in 1946 and Segal ${ }^{[125]}$ in 1970, respectively.

There are many extended versions of ECAE, such as equal channel multi-angular pressing (ECMAP), ${ }^{[128]}$ rotarydie ECAP, ${ }^{[129]}$ cross-ECAP, ${ }^{[130]}$ T-shaped ECAP,${ }^{[131]}$ multi-pass ECAP, ${ }^{[132]}$ torsional- equal channel angular pressing (T-ECAP), ${ }^{[133]}$ and incremental ECAP (I-ECAP). ${ }^{[134]}$

The ECAE process was considered for fabricating composite aluminum/copper clad rods. ${ }^{[135]}$ Metal forming techniques, such as forward extrusion, ECAE and hydrostatic extrusion, were also used to create a bonding which involves solid state diffusion mechanism at the interface. 
In addition to the traditional ECAP/ECAE methods, a number of relatively modern architectured joining operations have also been used to fabricate metal-composites. Examples of these are confined high pressure torsion, "axisymmetric forward spiral composite extrusion" (AFSCE) and fiber reinforced metal-matrix composite fabrication.

\subsubsection{High Pressure Torsion Process (HPT)}

The prospect and potentials of HPT have intrigued various researchers to understand the changes in bulk and powder material properties on the HPT processed samples. ${ }^{[136]}$ Zhilyaev and Langdon ${ }^{[136 a]}$ explained the HPT process and its parameters while other researchers investigated the homogeneous deformation during the HPT process. ${ }^{[136 \mathrm{~b}-\mathrm{d}]}$

The HPT process has been widely studied for aluminum powder compaction and grain refinement ${ }^{[117,137-141]}$ and for metal bonding ${ }^{[142]}$ at room temperature. The process parameters include the number of revolutions, pressure, rotation direction and rotation speed for the lower punch while the upper punch is fixed. The bottom punch rotation and longitudinal pressure are applied simultaneously. This develops a combined large compressive and shearing stress in the material.

It is highly desirable that powder fabrication is performed at ambient temperature to avoid the heating effects caused by sintering on the green compact. Use of HPT for powder processing at ambient temperature eliminates an additional sintering step, to obtain a high strength and near full density metal-composite.

Moreover, HPT enhances the strength of material due to the cold working at room temperature, which is below the re-crystallization temperature of the metal particles. Powder processing has been performed using HPT by several researchers. Some examples of the processing conditions are summarized in Table 1.

The deformed particles' morphology and heterogeneity of properties have not been studied adequately in these examples.

Confined high pressure torsion (CHPT), a variation of HPT, was utilized by Sapanathan et al. to produce composite metals by "powder compaction" [94] and "sheathed powder compaction". [144] The latter included two types of metal-composites: powder-powder bonds between Al particles and powder-metal bonds between Al-particles and a copper sheath. The CHPT process requires low-moderate processing conditions (e.g., 2 rotations and only $1.5 \mathrm{GPa}$ applied pressure ${ }^{[94]}$ ) compared to conventional HPT technique. Moreover, it fabricates a final product with "near zero external shape change" due to the confined nature of the process. ${ }^{[94]}$ Initial experiments were performed using $16 \mathrm{~mm}$ nominal size punches and dies to process the material. The test rig assembly press is shown in Figure 6. A longitudinal perspective view of the CHPT assembly is shown in Figure $6 \mathrm{~b}$. The bottom punch facilitates the rotation of the material about the vertical axis. To avoid un-wanted flash

Table 1. A summary of aluminum alloy powders processed using the HPT process. D: diameter and T: thickness (in $\mathrm{mm}$ ).

\begin{tabular}{|c|c|c|c|c|c|c|c|c|c|}
\hline \multirow[b]{3}{*}{ Details } & \multicolumn{9}{|c|}{ Source } \\
\hline & \multicolumn{2}{|c|}{ Kaneko et al. ${ }^{[143]}$} & \multicolumn{2}{|c|}{ Botta et al. ${ }^{[137]}$} & \multirow{2}{*}{$\begin{array}{l}\text { Yavari } \\
\text { et al. }{ }^{[138]}\end{array}$} & \multirow{2}{*}{$\begin{array}{l}\text { Bachmaier } \\
\text { et al. }^{[139]}\end{array}$} & \multirow{2}{*}{$\begin{array}{l}\text { Lee } \\
\text { et al. }{ }^{[140]}\end{array}$} & \multicolumn{2}{|c|}{$\begin{array}{l}\text { Tokunaga } \\
\text { et al. }{ }^{[141]}\end{array}$} \\
\hline & Case 1 & Case 2 & Case 1 & Case 2 & & & & Case 1 & Case 2 \\
\hline Purity (\%) & $\begin{array}{l}\text { Al with } 5 \% \\
\text { of }(\mathrm{Mg})\end{array}$ & $\begin{array}{c}\text { Al with } 20 \% \\
\mathrm{Mg}\end{array}$ & $\mathrm{Al}_{90} \mathrm{Fe}_{7} \mathrm{Z}_{3}$ & $\mathrm{Al}_{84} \mathrm{Y}_{3} \mathrm{Ni}_{8} \mathrm{Co}_{4} \mathrm{Zr}_{1}+\mathrm{SiC}$ & $\begin{array}{c}\mathrm{Al}_{90} \mathrm{Fe}_{5} \mathrm{Nd}_{5} \\
(90 \text { at\% } \mathrm{Al} \\
\text { powder })\end{array}$ & $\begin{array}{l}99.5 \% \text { purity of } \mathrm{Al} \\
\text { powder }\end{array}$ & Al-7.5\%Mg & $\begin{array}{c}99.99 \% \text { purity } \\
\text { Al with } 5 \% \\
\text { mass of } \\
\text { fullerenes }\end{array}$ & $\begin{array}{c}99.99 \% \\
\text { purity Al } \\
\text { only }\end{array}$ \\
\hline Powder size $(\mu \mathrm{m})$ & $\begin{array}{l}75 \text { in } \\
\text { diameter } \\
\text { (spherical } \\
\text { form) }\end{array}$ & $\begin{array}{c}75 \text { in } \\
\text { diameter } \\
\text { (spherical } \\
\text { form) }\end{array}$ & $\begin{array}{c}\text { 5-20 } \\
\text { (mechanical } \\
\text { alloying) }\end{array}$ & $\begin{array}{c}5-20 \\
\text { (spherical form) }\end{array}$ & $\begin{array}{c}25 \text { or less in } \\
\text { diameter } \\
\text { (spherical } \\
\text { form) }\end{array}$ & $\begin{array}{l}\text { Mean particle size } \\
\quad \text { of } 90 \& 1.3\end{array}$ & $\mathrm{~N} / \mathrm{A}$ & $\mathrm{N} / \mathrm{A}$ & $\mathrm{N} / \mathrm{A}$ \\
\hline $\begin{array}{l}\text { Initial dimensions } \\
\text { of sample }\end{array}$ & $\begin{array}{c}D=10 \\
T=0.25\end{array}$ & $\begin{array}{c}D=10 \\
T=0.25\end{array}$ & $\mathrm{~N} / \mathrm{A}$ & $\mathrm{N} / \mathrm{A}$ & $\begin{array}{l}D=10 \\
T=0.3\end{array}$ & $D=8 T=0.8$ & $\mathrm{~N} / \mathrm{A}$ & $D=10 T=0.25$ & $\begin{array}{c}D=10 \\
T=0.25\end{array}$ \\
\hline Pressure (GPa) & 2.5 & 6 & 5 & 5 & 5 & 4 & 6 & $2.5^{*}$ & 2.5 \\
\hline $\begin{array}{l}\text { Rotations, } N . \text { and } \\
\text { speed rpm, } \omega\end{array}$ & $N=40$ & $N=60$ & $\begin{array}{l}N=5 \\
\omega=1\end{array}$ & $\begin{array}{l}N=5 \\
\omega=1\end{array}$ & $\mathrm{~N} / \mathrm{A}$ & $\begin{array}{l}N=25 \\
\omega=0.2\end{array}$ & $N=5$ & $\begin{array}{c}N=15 \\
\omega=1\end{array}$ & $\begin{array}{c}N=15 \\
\omega=1\end{array}$ \\
\hline $\begin{array}{l}\text { Final dimensions } \\
\text { of sample }\end{array}$ & $\begin{array}{l}D=10 \\
T=0.7\end{array}$ & $\begin{array}{c}D=10 \\
T=0.7 \mathrm{~mm}\end{array}$ & $\begin{array}{c}D=7 \\
T=0.3\end{array}$ & $\begin{array}{c}D=7 \\
T=0.3\end{array}$ & $\mathrm{~N} / \mathrm{A}$ & $\mathrm{N} / \mathrm{A}$ & $\begin{array}{l}D=10 \\
T=0.5\end{array}$ & $\mathrm{~N} / \mathrm{A}$ & $\mathrm{N} / \mathrm{A}$ \\
\hline $\begin{array}{l}\text { Grain size after } \\
\text { compaction }(\mathrm{nm})\end{array}$ & $80 \mathrm{~nm}$ & $45 \mathrm{~nm}$ & $\mathrm{~N} / \mathrm{A}$ & N/A & $\mathrm{N} / \mathrm{A}$ & $\begin{array}{c}145 \mathrm{~nm} \text { for } 90 \mu \mathrm{m} \\
104 \mathrm{~nm} \text { for } 1.3 \mu \mathrm{m} \\
\text { particles }\end{array}$ & $\begin{array}{c}19 \mathrm{~nm} \\
(+/-2 \mathrm{~nm})\end{array}$ & $80 \mathrm{~nm}$ & $500 \mathrm{~nm}$ \\
\hline $\begin{array}{l}\text { Micro-hardness } \\
(H v) \text { or yield } \\
\text { strength }(\mathrm{MPa})\end{array}$ & $202 \mathrm{Hv}$ & $288 \mathrm{Hv}$ & $\begin{array}{c}3580 \mathrm{MPa} \\
(+/-150 \\
\mathrm{MPa})\end{array}$ & $\begin{array}{c}4600 \mathrm{MPa} \\
(+/-100 \mathrm{MPa})\end{array}$ & $\begin{array}{c}3100 \mathrm{MPa} \\
(+/-50 \mathrm{MPa})\end{array}$ & $\begin{array}{c}880 \mathrm{MPa} \text { for } 90 \mu \mathrm{m} \\
\text { and } 1300 \mathrm{MPa} \text { for } \\
1.3 \mu \mathrm{m} \text { particles }\end{array}$ & $\begin{array}{c}3400 \mathrm{MPa} \text { at } \\
\text { center, } 3800 \\
\mathrm{MPa} \text { at } \\
r=5 \mathrm{~mm}\end{array}$ & $\begin{array}{c}382.5 \mathrm{MPa} \text { at } \\
\text { center, } 1157 \\
\mathrm{MPa} \text { at } \\
r=3 \mathrm{~mm}\end{array}$ & $\begin{array}{c}\approx 382.5 \\
\text { MPa. at } \\
\text { center }\end{array}$ \\
\hline
\end{tabular}



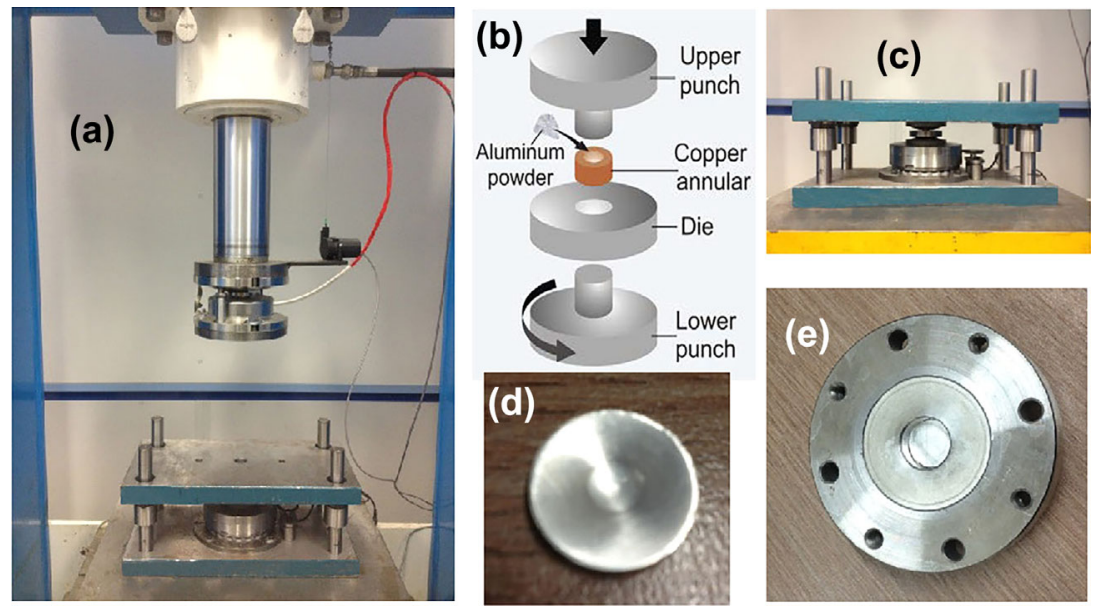

Figure 6. The CHPT test rig a) The process on the hydraulic press, b) Schematic presentation of the CHPT process with copper annular and aluminum powder materials to make a metalcomposite, c) CHPT process assembly prior to the processing, d) aluminum dome shaped cap, and e) confined die-sample assembly after the process. ${ }^{[145]}$

out of materials through the punches - die clearances, and to trap the loose powder in place, small, thin, and dome-shaped aluminum disks were placed on the top and bottom of the sample (Figure 6d, e). ${ }^{[145]}$

\subsubsection{AFSCE Joining}

"Axisymmetric Forward Spiral Composite Extrusion" $(\mathrm{AFSCE})^{[145]}$ is an extrusion based process to fabricate round cylindrical metal-composites. Details on $\mathrm{Cu}$ cladding of $\mathrm{Al}$ samples can be found in Sapanathan et al. ${ }^{[144,145]}$ The longitudinal cross-section of the AFSCE assembly is illustrated in Figure 7a. It shows the AFSCE die with the punch positioned at the beginning of the extrusion process. The die (No.3) is shown near the middle region of the assembly. The assembly

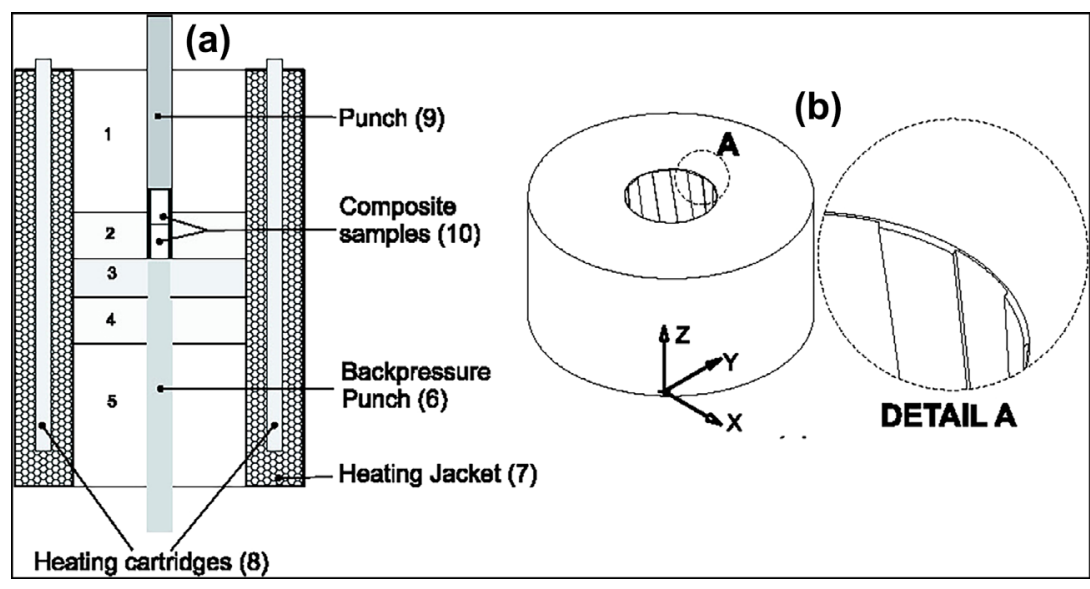

Figure 7. Schematic of the AFSCE process: a) The AFSCE die set with heating unit assembly, 1 and 5 punch guides, 2 and 4 containers and 3 is the AFSCE die. and b) two detailed views of AFSCE die 3. (Adopted with permission. ${ }^{[146]}$ 2013, Elsevier). during the process.

includes a chamber (No.1). A backpressure punch (No.6) is placed opposite the extrusion punch (No.9). This allows provision of a large hydrostatic pressure and is guided by part No.5. A heating jacket (No.7) facilitates the conductive heat transfer to the die assembly, which is heated using heating cartridges (No.8) and encloses the die assembly. Back pressure is applied using a hydraulic system. To prevent the backpressure punch causing any damage to the groove features in the die, a stepped punch was used to apply the back pressure. A composite core-clad type bimetallic sample (No.10) is fitted with a slide fit tolerance at the beginning of the process. To avoid longitudinal relative movement between the core and clad during the process and to prevent the flash out, small steel disks were placed on the top and bottom of each sample. A dummy sample was also placed on top of the main sample inside the chamber to avoid any damage to the punch and die

In the ECAE process, the extrusion ratio is almost zero. Contrary to AFSCE, the ECAE process is one of homogeneous deformation; in the AFSCE the tangential component of material flow changes from zero at along the center line to its maximum at the periphery of the sample. The tangential velocity component is responsible for a non-homogenous component of shear deformation in the sample that increases in the radial direction.

The main aim of AFSCE processing is to facilitate diffusion of materials at the interface, at an elevated temperature and a large hydrostatic pressure. ${ }^{[147]}$ The back pressure increases the hydrostatic pressure at their interface. In the existing literature, two possible mechanisms are considered to explain the bond formation between dissimilar metals, including 1) mechanical interlocking and 2) metallurgical bonding. The former is facilitated by a large pressure at the interface and the latter is enabled by a diffusion mechanism under the required processing conditions. A high pressure compensates for the requirement of holding time and facilitates the diffusion mechanism at the interface. ${ }^{[104,148]}$

The AFSCE extrusion rig and its "back pressure" setup are shown in Figure 8. Back pressure is applied to the system using a separate hydraulic unit which consists of a hand pump, needle valve, pressure relief valve and a pressure gauge, as shown in Figure 8c. Prior to the processing, the back pressure is set (typically about the yield strength of softer material) and applied via a hydraulic plunger (Figure 8d) bellow the AFSCE processing unit. The interior assembly of the die with spiral grooves and containers is shown in Figure 8e.

The composite $\mathrm{Al} / \mathrm{Cu}$ samples (Figure 8f) were obtained after AFSCE processing at 

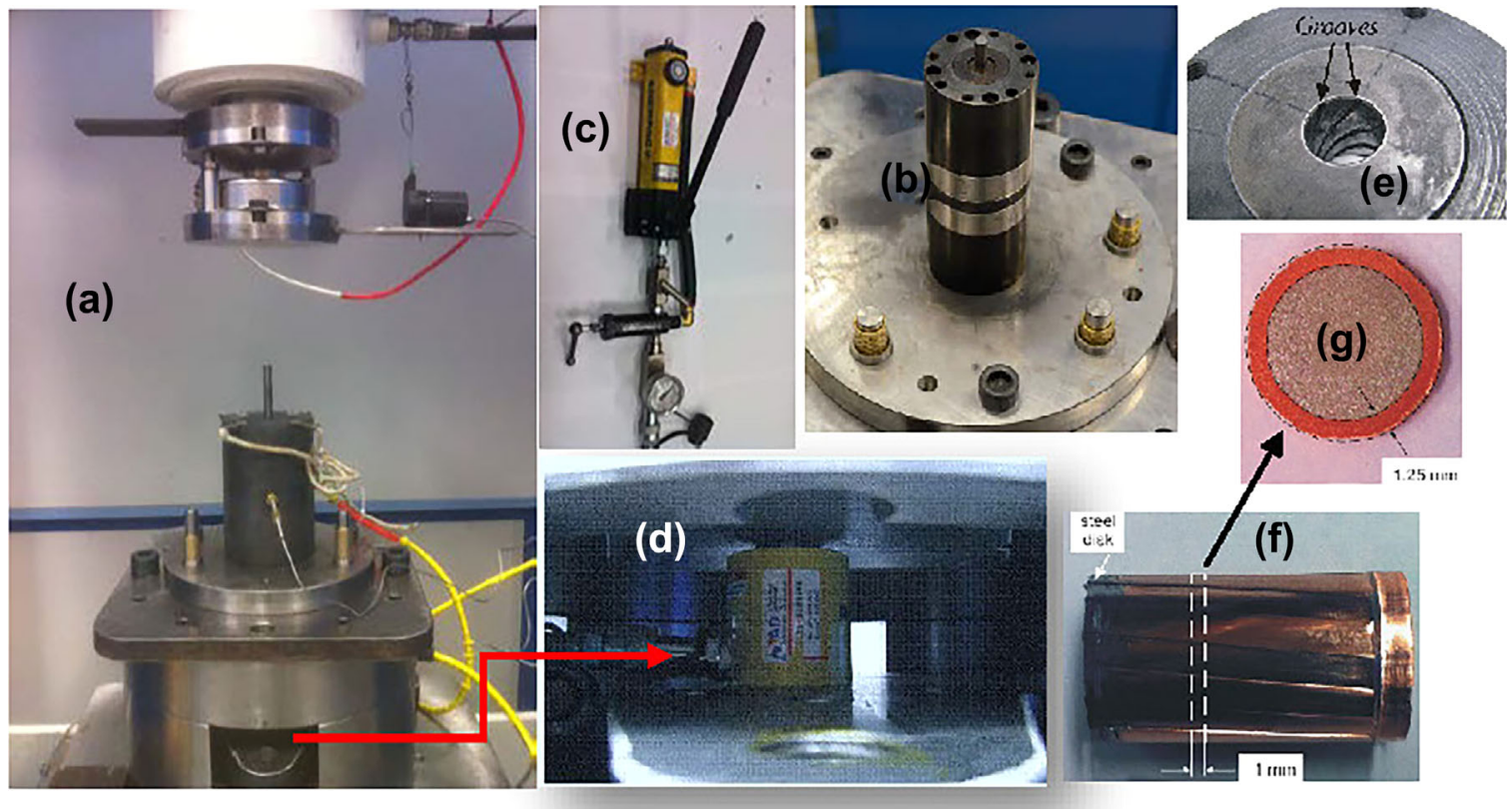

Figure 8. AFSCE process rig a): full view photo, b) assembly of the AFSCE processing unit c) hydraulic pump used to apply the back pressure via the lower plunger, d) hydraulic plunger to provide back pressure via lower punch, e)AFSCE die showing the arrangement of the helical grooves, $f$ ) fabricated aluminum-copper sample, and g) sliced sample used for bond strength measurement. (Insets g and f are adopted with permission. ${ }^{[146]} 2013$, Elsevier).

$300^{\circ} \mathrm{C}$ with a back pressure of $200 \mathrm{MPa}$. The lower punch is responsible for the back pressure (Figure $8 \mathrm{~d}$ ) and prevents $\mathrm{Al}$ flowing before $\mathrm{Cu}$ in a longitudinal direction due to the lower flow stress of $\mathrm{Al}$ compared to $\mathrm{Cu}$ and a higher friction between die-wall and the $\mathrm{Cu}$ clad compared to that between the clad and the $\mathrm{Al}$ core.

The die includes eight helical grooves with a depth of $0.15 \mathrm{~mm}$ and helix pitch of $305 \mathrm{~mm}$ (Figure 8e). The AFSCE die is $20 \mathrm{~mm}$ in length with a helix rotation angle of $23^{\circ}$ and a root diameter of $13 \mathrm{~mm}$. The material flow inside the grooves is facilitated by a chamfer of $0.15 \mathrm{~mm} \times 45^{\circ}$ which is located at the entrance of the die. To measure the bond strength of the metal-composite samples, composite slices with different thicknesses were prepared from the fabricated sample (sliced sample in Figure 8g) for a subsequent blanking test that will be explained in Section 4.5 of this article.

\subsubsection{Fiber Reinforced Metal Matrix Composite (FRMMC)}

An interesting case of metal-composites, "fiber reinforced metal matrix composite" (FRMMC), is shown in Figure 9. ${ }^{[149]}$ The process involves geometric locking of the wires to the deformed matrix by plastically twisting a pre-assembled composite sample. FRMMC processing prevents the sliding between wires and matrix when the fabricated composite is loaded or twisted axially. This situation eliminates the need for a bond between the matrix and its reinforcing wires. As a result, the intermediate layer does not introduce any weakening mechanism under a torsional or compressive loading of the composite metal. Khoddam et al. ${ }^{[150]}$ developed two solutions to estimate the torsional and compressive strengths of the metal-composite and verified the derivations experimentally. The locking, either due to geometrical or metallurgical (e.g., welding), does not change the presented derivations. However, in a more realistic model, the details of the interfacial metallurgical bonding (see, e.g., ${ }^{[150]}$ ) needs to be considered.

\subsection{Joining during Additive and Subtractive Manufacturing}

Additive Manufacturing (AM) employs single or multiple materials in layers. In both cases, integrity of the layers and their bonding together are key elements to determine the final strength of the manufactured part. With the recent increase in additive manufacturing technologies, traditional machining has been reclassified, in theory and terminology, as subtractive manufacturing (SM). Delicate SMs such as lithography are indirectly linked to the metal-composites as they allow fabrication of micro-channels which are commonly used to create an in situ liquid metal layer. This enables production of metal-composites with a range of non-metal constituents, which are very popular for medical and electrical applications.

The potential of cold gas dynamic spray, also known as cold spray (CS), for AM technology was investigated by Sova et al. ${ }^{[151,152]}$ They demonstrated fabrication of a new multimaterial deposition using a micro-nozzle device. "Steel-bronze bimetal samples" were produced by shaped metal deposition ${ }^{[153]}$ where a metal arc welding technology was employed to bond single pass multi-layers of mild steel and silicon bronze.

Ultrasonic additive manufacturing (UAM) was employed for dissimilar materials and complex geometries ${ }^{[154]}$ using very high power ultrasound waves with an increase in the amplitude (from 26 to $52 \mu \mathrm{m}$ ). It provided the required normal force (from 2.5 to 
(a)

(b)

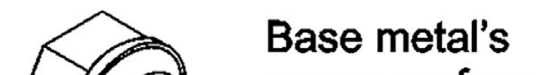
gauge surface

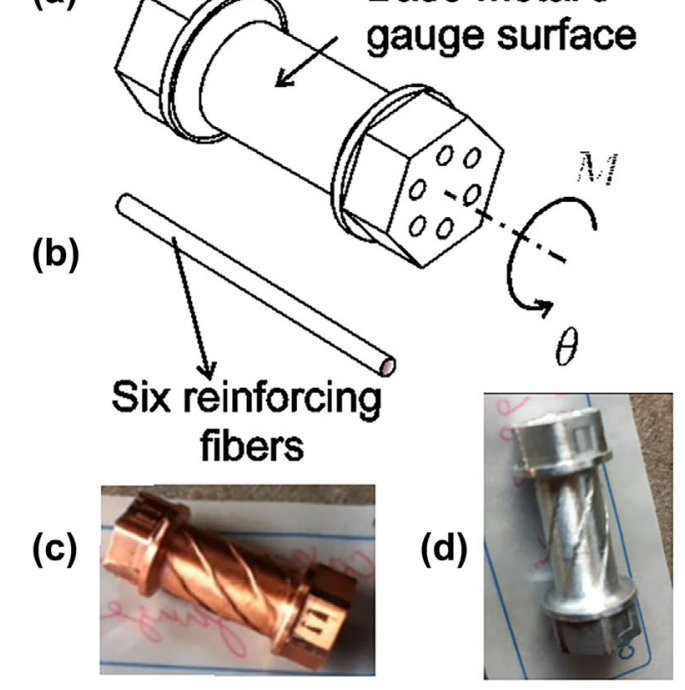

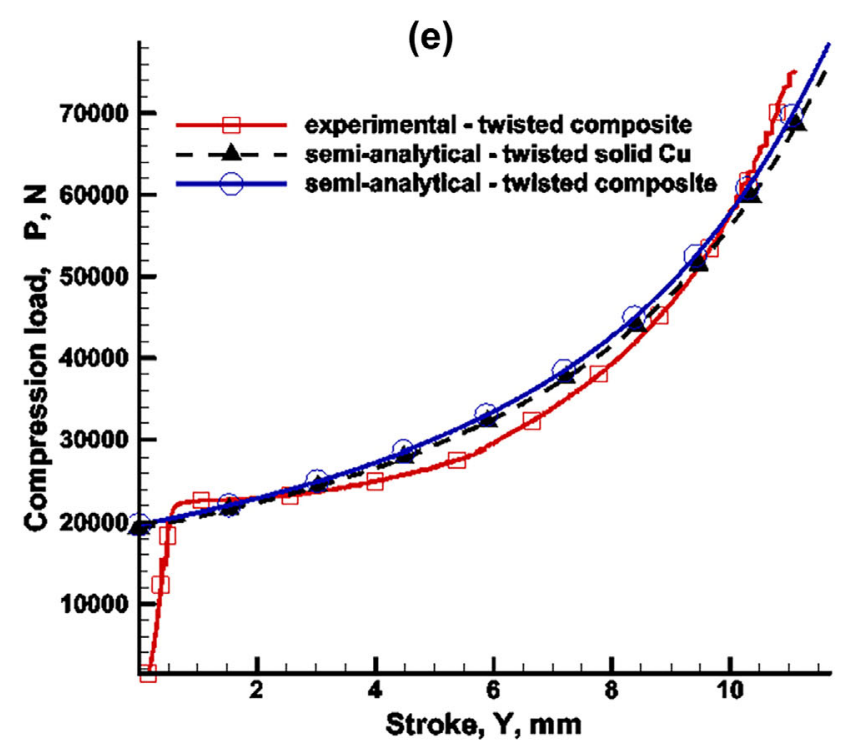

Figure 9. Fiber reinforced metal matrix composite; a) FBMC's fabrication, b) reinforcement steel fibers, c) processed Cu matrix, d) processed Al matrix, and e) experimental verification of the composite's strength model (Adopted with permission. ${ }^{[149]}$ 2015, Elsevier).

$33 \mathrm{kN}$ ) to join dissimilar materials. The UAM joined Al3003 and $\mathrm{Cu} 100$ and produced intermetallic phases at the interface.

Commonly used alloys for AM include Ti, Al, tool steels, super alloys, stainless steel, and refractory metals. Due to a strong demand for complex and low production volume titanium parts, Ti-6Al-4V alloy has been extensively studied by various researchers.

\section{Characterization of Bonding}

A direct approach to measure the "bonding strength" relies on the geometry of the interface and the loading while a bulk approach employs the law of mixtures and volume fraction of each component. When the strength and toughness of the composites are studied carefully, we shall notice that the strength of the interfacial bond may be responsible for all the differences between a satisfactory metal-composite and an inadequate one. Interestingly, the interface is the natural place to accommodate the impurities, residuals, external materials, or layers produced by uncleaned contact surfaces at the interface. Although this can be minimized, it is practically inevitable for many existing fabrication processes. Consequently, the interface could become the weakest zone for the fabricated hybrid structure. ${ }^{[144,145,150,155]}$ The layer makes modeling of the interface even more complex.

\subsection{Degrees of Freedom to Identify Joining Modes}

While the interface geometry could be quite complex, some primitive contact types can be used to demonstrate the modes of joining, to develop simple modeling of the composite's strength and to identify the failure modes of a metal-composites in-service. The basic contact types include: revolute, spiral, prismatic, cylindrical, planar, and spherical. Figure 10 shows the contact types, components of the metal-composite (red and blue) and degrees of freedom (DOF) for each type. Also, a thin intermediate layer might exist between the components which is not shown here. A DOF is defined as a direction in which an independent motion can potentially occur between the components (see, e.g., ${ }^{[156]}$ ).

The classifications shown in Figure 10 are useful to identify the composite's critical modes of loading, failure, and the bonding strength. Examples of these will be given in the following sections when they are employed to design an experimental setup to measure the response of the composite to a given loading and to calculate the bonding strength corresponding to each critical load. For the translational DOFs, when the loading is normal or parallel to the interface, a uniaxial test (tension or compression) or a shear test may be utilized, respectively, to identify the corresponding bonding strength. When material is subjected to bending, the strength depends on an equivalent moment of inertia. To develop an analysis based on the contact interaction, it is also necessary to know the loading types and the likelihood that they are part of the composite's working conditions.

\subsection{Mechanical Tests of Diffusion Based Welded Joints}

Generally, diffusion based joints produce all the contact interaction type shown in Figure 10. Typically, the weld strength is measured using a dedicated shear lap test ${ }^{[157]}$ or a uniaxial test.

An example of DBW joining is the fabrication of a three ply clad sheet of $\mathrm{Cu}, \mathrm{Al}$ and stainless steel using a hot rolling process at $350^{\circ} \mathrm{C} .{ }^{[158]}$ After the fabrication of the 3 ply clad sheet, the samples were annealed at $100,200,300$, and $400^{\circ} \mathrm{C}$ and the mechanical properties of the sample and its interfacial properties ${ }^{[159]}$ investigated using a tensile test. Moreover, $\mathrm{Al}_{2} \mathrm{Cu}$, 
(a)

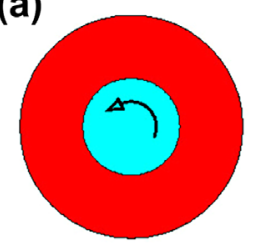

(b)

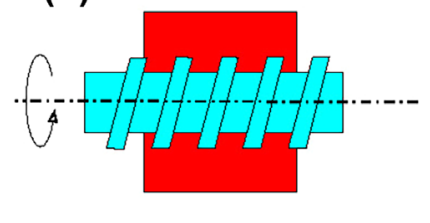

(e)

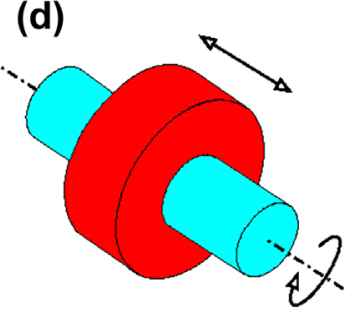

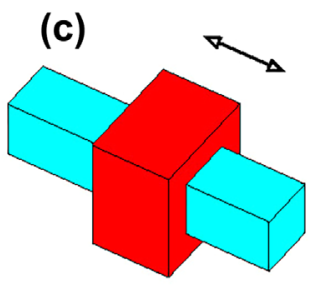

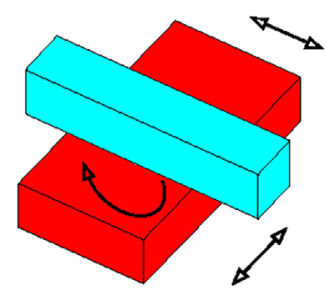

(f)

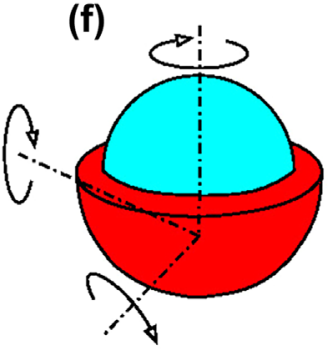

Figure 10. Types and degrees of freedom for simple contact interactions between the components; a) Revolute (1 DOF, 1 rotational), b) Screw/Spiral (1 DOF, 1 rotational), c) Prismatic (1 DOF, 1 translational), d) Cylindrical (2 DOF, 1 translational +1 rotational), e) Planar (3 DOF, 2 translational +1 rotational), and f) Spherical (3 DOF, 3 rotational).

(typically $5-20 \mu \mathrm{m}$ ) and the heterogeneous distribution of the particles in the fabricated sample. ${ }^{[144]}$ Instead, small specimen techniques $^{[159]}$ (e.g., micro-shear punch) were used to characterize a range of mechanical properties such as strength and ductility in a relatively small zone (e.g., ${ }^{[160]}$ and ${ }^{[161]}$ ) with limited availability of the fabricated materials.

"Cylindrical interaction" (Figure 10d) can be used to model the metal-powder interface developed by the cylindrical "sheathed powder compaction technique" samples. ${ }^{[144]}$ The simplified model ignores the intermediate layer between powder particles and a solid sheath. Given the bond's "translational degree of freedom", the ratio of critical shearing load to the interface area represents the bonding strength.

Experimental setup for the micro shear punch and a typical distribution of the "particle-particle bonding strength" for a sheathed powder compacted sample are shown in Figure 11. The micro shear punch measurements ${ }^{[144]}$ were used to interpret a copper aluminum intermetallic compound (IMC) was formed at the interface of the $400^{\circ} \mathrm{C}$ annealed sample, and it was identified using Scanning Electron Microscopy (SEM). ${ }^{[158]}$ The Vickers indentation test was used in this study to confirm brittleness of the $\mathrm{Al}_{2} \mathrm{Cu}$ and its reduced ductility. ${ }^{[158]}$

One of the main advantages of DBW techniques is their applicability in AM operations. Liu et al. ${ }^{[153]}$ demonstrated this (shaped metal deposition) to fabricate steelbronze hybrid-metal samples. The interface's tensile strength was characterized and the tensile strength of the bimetal reached $305 \mathrm{MPa}$; the fracture occurred near the middle of bronze side. The results showed a good adhesion at the interface between steel and bronze, "metallurgical based bonding", without cracks or pores. The results showed no $\mathrm{Cu}$ element on the steel side, while $\mathrm{Fe}$ element entered the bronze side in the form of large particles. ${ }^{[153]}$

\subsection{Sheathed Powder Compaction}

Metal-composite samples fabricated by "sheathed powder compaction" by CHPT ${ }^{[143]}$ produced two types of metal-composite bonds: powder-powder and powder-solid bonds. The DOF approach presented in Section 4.1 is not suitable to characterize the bonding strength of the compacted powder due to the particles' complex geometry, their extremely small size
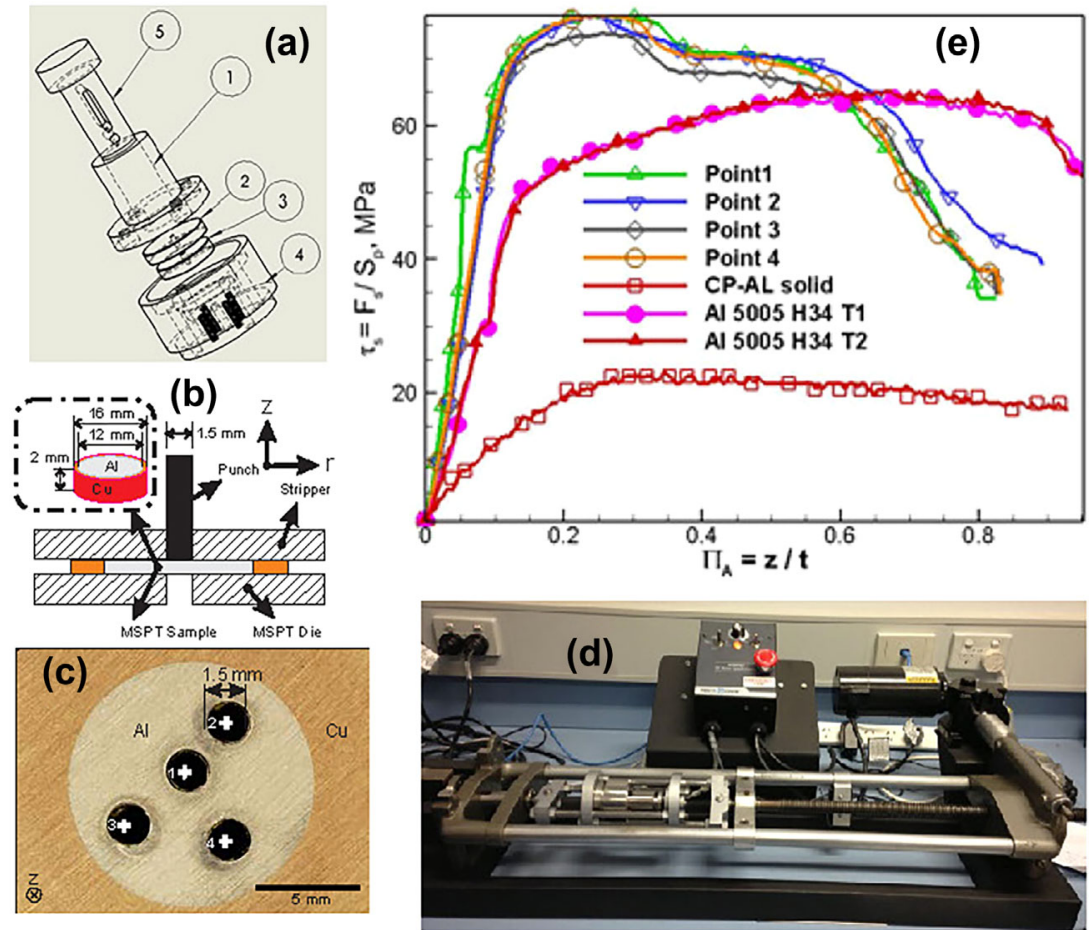

Figure 11. Characterizing compacted powder bonding using a micro shear punch (MSP) a) MSP exploded view: 1) linear bearing (guide), 2) stripper, 3) die, 4) anvil, and 5) punch holder, b) schematic assembly of sliced composite sample and MSP, c) 4 sampling points for MSP test of the compacted aluminum powder, d) experimental rig for MSP's load displacement measurement, and e) post processed bonding strength for the sampling points and comparison with reference values [it also includes the reference MSP curves obtained for the same thickness of commercially pure aluminum alloy indicated by CP-Al solid, and two test cases on $5 x x$ series aluminum]. (Insets b, $c$ and e are reproduced from. ${ }^{[144]}$ ). 
bonding strength within a metal-composite's powder compacted zone. This provided the bonding strength in an average sense for a small footprint of $0.5-1 \mathrm{~mm}$ diameter. Also, the morphology of the compacted powder and their deformed configurations (splats) were examined in three dimensions within the sample. ${ }^{[144]}$

The bonding between powder and its sheath metal can be characterized using a dedicated blanking test ${ }^{[145]}$ considering a failure mode of the "cylindrical contact" in Figure 10d and choosing the punch diameter to be equal and concentric to inner diameter of the sheath.

\subsection{Extrusion Based Bonding and ECAE}

$\mathrm{Al} / \mathrm{Cu}$ clad rods were fabricated using an indirect extrusion and drawing process. ${ }^{[161]}$ Kwon et al. performed a sensitivity analysis on the bonding strength of the $\mathrm{Al} / \mathrm{Cu}$ clad interface and recommended a temperature range between 573 and $623 \mathrm{~K}$ with an extrusion ratio of 21.39 to achieve the optimum extrusion conditions. ${ }^{[161]}$ They noticed a fracture of the $\mathrm{Cu}$ clad during the extrusion when temperature increased above $623 \mathrm{~K}^{[161]}$ In their experiments below $523 \mathrm{~K}$, on an initial $\mathrm{Cu}$ thickness of $6 \mathrm{~mm}$ with an extrusion ratio of 6.68 , the bonding strength was approximately $10 \mathrm{MPa} \cdot{ }^{[161]}$ At the same extrusion ratio of 6.68 with a temperature of $623 \mathrm{~K}$, they observed a diffusion layer thickness (DLT) of $1.6 \mu \mathrm{m}$ while the bonding strength of the fabricated sample increased to $60 \mathrm{MPa} .{ }^{[161]}$ They reported an increase in the bonding strength, respectively, to $1.8 \mu \mathrm{m}$ and $65 \mathrm{MPa}$ at a given extrusion ratio of $21.39 .{ }^{[161]}$ The DLT and the bonding strength were also, respectively, increased to $3 \mu \mathrm{m}$ and $75 \mathrm{MPa}$ after annealing the sample for $1 \mathrm{~h}$ at $573 \mathrm{~K} \cdot{ }^{[161]}$

Eivani and Taheri ${ }^{[136 c]}$ employed ECAE to fabricate metalcomposite samples of $\mathrm{Al} / \mathrm{Cu}$ clad rod at $350^{\circ} \mathrm{C}$. They tested the bonding strength of their "as extruded sample" using a blanking test. This was carried out using a sliced sample of $5 \mathrm{~mm}$ thickness. ${ }^{[136 \mathrm{c}]}$ The samples were annealed at $300^{\circ}$ for $1 \mathrm{~h}$ before the test, which identified the increase in bonding strength. It was suggested that multiple passes of ECAE processing increased the bonding strength. ${ }^{[136 c]}$

Similarly, Eslami, and Taheri investigated the diffusion bonding of $\mathrm{Cu}$ clad $\mathrm{Al}$ rod using the ECAE process ${ }^{[136 \mathrm{~b}]}$ under different conditions. Temperature was varied from 100 to $225^{\circ} \mathrm{C}$ in steps of $25^{\circ} \mathrm{C}$ and the shear strength of the bonding was tested at holding times of $20,40,60,80$, and $100 \mathrm{~min}$ at each temperature. ${ }^{[136 \mathrm{~b}]}$ A good bonding was reported for processing temperature of $200^{\circ} \mathrm{C}$ with a holding time of 60 to $80 \mathrm{~min} .{ }^{[136 \mathrm{~b}]} \mathrm{It}$ was also suggested that the bonding strength was adversely affected by increasing the temperature above $120^{\circ} \mathrm{C}$, due to formation of brittle intermetallic compound in a vacuum free processing environment. ${ }^{[136 \mathrm{~b}]}$

Another study reported that $\mathrm{Al}$ welded with $\mathrm{Cu}$ in ambient conditions using the ECAE process. ${ }^{[136 a]}$ The bonding strength of the $\mathrm{Al} / \mathrm{Cu}$ clad sample was found to be $33 \mathrm{MPa}$ using a blanking test, which is comparable with yield strength of aluminum. ${ }^{[136 a]}$ For a composite ECAE sample with a rectangular section, the "prismatic interaction" in Figure 10c was used as the failure mode to characterize the metal-composite's bonding strength. Although the experiment was performed under ambient conditions, the bonding strength was tested after annealing the final product at $250^{\circ} \mathrm{C}$ for $1 \mathrm{~h} .^{[136 \mathrm{a}]}$

In addition to the experimental investigations, researchers have developed some analytical frameworks on the bimetallic extrusion processes. Hartley developed an upper bound solution for composite rod extrusion process ${ }^{[162]}$ and in this theoretical formulation assumed a piecewise homogeneous process. ${ }^{[162]}$ However, a homogeneous material flow is unrealistic in a non-proportional bimetallic forming process with dissimilar materials. ${ }^{[109]}$ Metal flow of bimetallic extrusion was characterized for combinations of "a soft sleeve with a hard core" and "a hard sleeve with a soft core" by Tokuno and Ikeda using analytical and experimental studies. ${ }^{[163]}$ Their formulation included a velocity field in which the material flow planes were not considered as parallel. ${ }^{[163]}$ In their analytical formulation, they assumed a velocity field similar to that of a typical extrusion process with no tangential velocity component. Avitzur et al. investigated a core fracture behavior and a sleeve fracture behavior using a velocity field analysis in various composite extrusion processes. ${ }^{[164]}$

Another study provided a theory for an axisymmetric bimetallic tube extrusion using the slab method. ${ }^{[165]}$ Berski et al. presented a theoretical formulation for a bimetallic rod in a double reduction die with two extrusion ratios. They presented case studies using "FORGE2" commercial software. $^{[166]}$ Haghighat and Asgari developed a generalized spherical velocity field for a bimetallic extrusion. ${ }^{[167]}$ However, they did not provide a complete theoretical stress analysis solution for their solid bimetallic extrusion. The extrusion ratio for a composite sample depends on several variables, including the geometrical parameters, materials properties and the process parameters. Rhee et al. performed bimetallic extrusion with the extrusion ratios of $8.5,19$, and 49 , while Kwon et al. considered a forward extrusion with an extrusion ratio of 6.98 to $21.39 .^{[111,161]}$ Sliwa argued that the single material extrusion ratios are not necessarily applicable to both the extrusion ratios of core and sleeve. ${ }^{[109]}$ Neither of these works provided a sensitivity analysis to support their chosen extrusion ratios.

A parametric optimization study of bimetallic rod extrusion was conducted for Al alloy2014 (core) and Al alloy6063 (sleeve). ${ }^{[168]}$ To optimize the extrusion length of the bimetallic rod, the researchers used a coupled physical and numerical

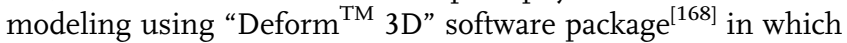
the lengths of the core and sleeve were varied to optimize the sample length by comparing the free end of the extruded samples. ${ }^{[168]}$ Khosravifard and Ebrahimi conducted a numerical study for a bimetallic extrusion of composite $\mathrm{Al} / \mathrm{Cu}$ clad rods ${ }^{[169]}$ using the LS-DYNA commercial package. They investigated the force-displacement, radial strain and interfacial strength ${ }^{[169]}$ in their fabricated sample and showed a uniform radial strain in a bimetal extrusion.

Contrary to the above cases, both "twist extrusion"[170] and "axisymmetric forward extrusion" ${ }^{[171]}$ include a tangential velocity in their velocity field. The latter process has been employed to bond metals and to produce bimetallic rods. ${ }^{[155]}$ The mechanical characterization AFSCE samples, will be reviewed next. 

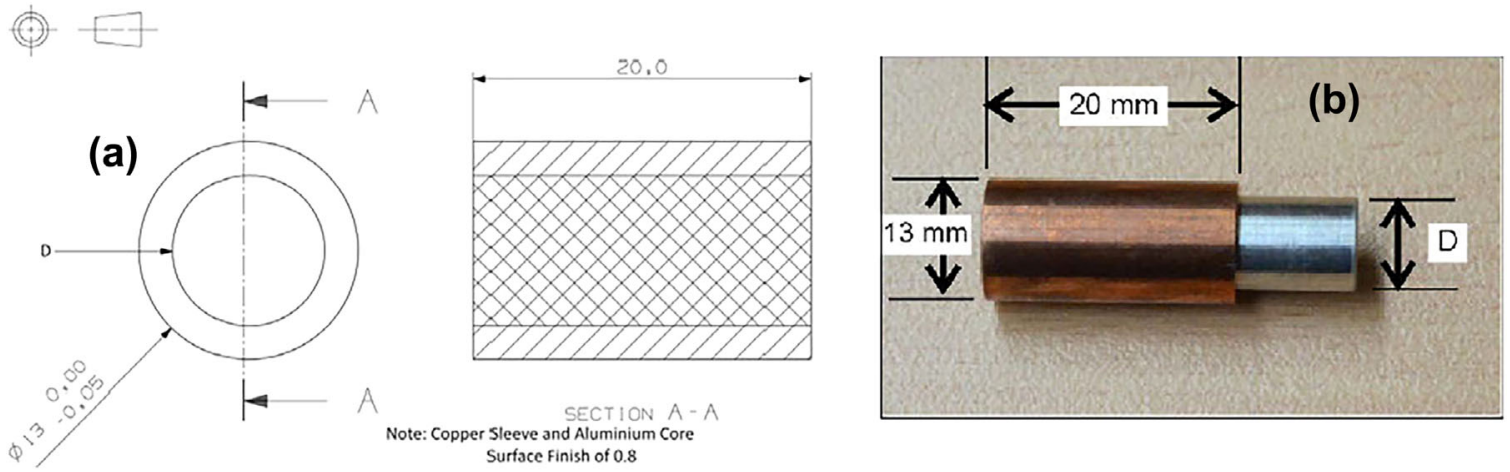

Figure 12. Composite sample before processing a) manufacturing drawings to show the main dimensions of the composite sample b) the sample's image with Cu clad and Al core. ${ }^{[155]}$ (Adopted with permission. ${ }^{[146]}$ 2013, Elsevier).

\subsection{Bond Strength Measurement of AFSCE Samples}

Composite samples with a commercially pure copper (C11000 with $99.90 \% \mathrm{Cu}$ ) clad and a pure cast $\mathrm{Al}$ core were fabricated using AFSCE experiments at $300^{\circ} \mathrm{C}$ and an applied backpressure. ${ }^{[155]}$ Dimensions for $\mathrm{Cu}$ clad (sleeve) and $\mathrm{Al}$ core are shown in Figure 12. A low clearance slide fit tolerance of H7g6 (ISO 286-2) was chosen for the diameters of the core and the clad. The slide fit minimized trapped air between the core and clad during the process, thus it minimized the risk of oxide formation at the interface. More detail of the processing parameters is available in ref. [150].

To investigate the effective bond formation between copper and the aluminum samples, five different combinations of samples were produced by varying $D$, the inner diameter, (Figure 12b), equal to 11.0, 10.5, 10.0, 9.5, and $9.0 \mathrm{~mm}$.

Although both AFSCE and ECAE joining methods are extrusion based, their bond types are different. The contact between the two metals in AFSCE resembles that of the clad metal contact with AFSCE die. Therefore, the contact between the core and clad metals after the process can be represented by the screw/spiral contact in Figure 10b. The only DOF for the screw type interaction is the rotational one. However, it is unlikely that this DOF becomes a failure mode due to the high torque required to overcome the friction at the contact. ${ }^{[172]}$ Therefore, AFSCE develops a mechanical interlocking between the components.

The screw/spiral bonding by AFSCE is complex. Simplifying the contact interaction type to a cylindrical one, a blanking test can be used to characterize the bonding strength in an average sense due to a longitudinal failure mode. ${ }^{[150]}$ Thus, a modified axisymmetric dedicated blanking test (DBT) was developed and completed for this experiment (Figure 10d with longitudinal DOF).

The extruded composite samples were sliced, normal to the extrusion axis, by "wire cutting" in preparation for the blanking test (Figure 13a, loaded with the AFSCE's sliced sample). The extruded composite specimen with $10.5 \mathrm{~mm} \mathrm{Al}$ core was sliced to obtain 1 ,
1.5 , and $2 \mathrm{~mm}$ thickness specimens. The slices were tested subsequently by blanking using DBT to measure their bonding strength. The results of the blanking were interpreted with a numerical assisted inverse identification modeling due to complexities of strain and stress development at the metalcomposite sample and the ambiguities caused by the blanking's clearance.

To obtain a reference stiffness curve, an $\mathrm{Al}$ disk sample of $1 \mathrm{~mm}$ thickness was machined from an identically extruded section and blanked using the corresponding $10.5 \mathrm{~mm}$ DBT set. The solid $1 \mathrm{~mm}$ Al sample required the maximum shear load of $F_{r}=1950 \mathrm{~N}$ to fail and exhibited a typical elastic-plastic behavior as shown in Figure 13b. Similar measurements for composite samples with various thicknesses revealed that the maximum blanking load increased with an increase of thickness of AFSCE specimens. It can also be seen in Figure 13b that the correlation between the thickness and maximum required force is non-linear. This is because the DBT samples with higher thicknesses experience both simple shear and bending failure modes. Further to this, the composite sample with $1 \mathrm{~mm}$ thickness required $1289 \mathrm{~N}$ shear load to fail at the interface. This is below the force requirement to cause a fully mature failure of the Al reference sample, $F_{r}=1950 \mathrm{~N}$. The lower than expected strength of the composite sample is most likely due to the presence of an intermediate interfacial layer
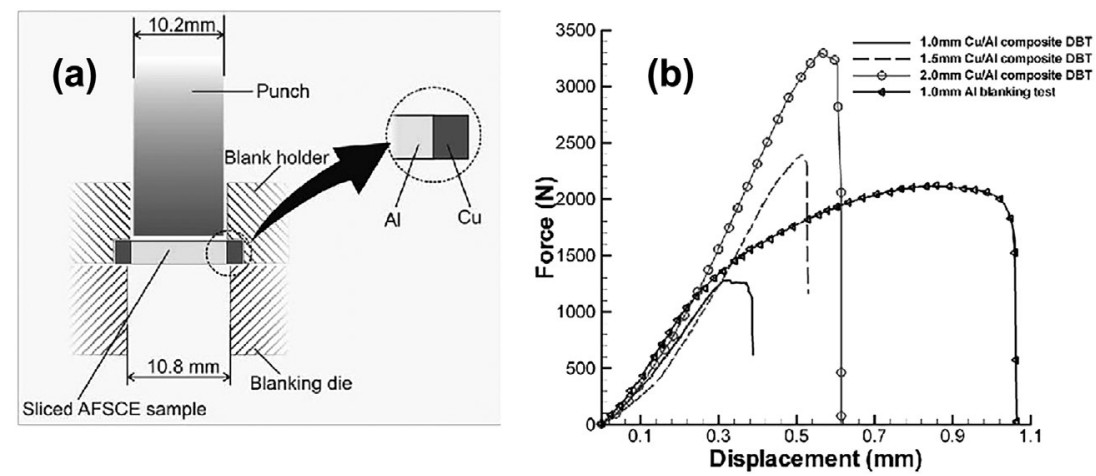

Figure 13. The dedicated blanking test, a) Section view of DBT rig to measure bonding shear strength, b) DBT' results plotted for shear force against the punch stroke. ${ }^{[150]}$ (Adopted with permission. ${ }^{[146]}$ 2013, Elsevier). 
between $\mathrm{Al} / \mathrm{Cu}$. Moreover, the sudden drop in the DBT results, Figure 13b, indicates the brittle nature of the interface. The lower than expected strength for the bond was also studied numerically using a dedicated finite element model. It explains that the stress discontinuity and stress concentration at the interface were due to sudden variation of the composite specimen properties at the boundary, suggesting a brittle failure from a continuum mechanics point of view.

\subsection{Finite Element (FE) Characterization of the Extrusion Based Joining Processes}

As far as the bonding strength is concerned, the second constituent serves as a stress (strain)-concentrator ${ }^{[173]}$ and can reduce the bonding strength. To maintain a kinematically compatible condition across the interface, a stress gradient develops at the vicinity and inside the bonding zone due to different constitutive properties of the two materials. To handle this by a finite element model and to capture the gradient adequately, special elements should be used.

Sapanathan et al. ${ }^{[174]}$ employed a finite element model to represent the complex interface for their AFSCE samples. In their model, the bond was represented as an intermediate layer. To characterize the bond strength, an experimental setup was used with the DBT to measure the loading behavior of the sliced AFSCE sample.

An axisymmetric 2D schematic for the assembly of the DBT test configuration, including a test sample, is shown in Figure 14a. It includes three major components; the blank holder punch and die. An axisymmetric model was used to perform the numerical modeling using Abaqus/explicit module. Figure 14b shows the mesh employed in the numerical model for the longitudinally sliced composite sample at the beginning of DBT. The numerical model simulates the blanking process to investigate the role of each test parameter. The parameters included sample thickness, clearance between punch and die and fillet diameter of the tools.

2D, axisymmetric, bi-linear solid elements with 4 nodes (CAX4R with 2 degree of freedom per node), were used to model the bimetallic material. The blank holder, punch and die were treated as rigid in the simulation. A sufficiently fine mesh was chosen to capture the large gradient of the stress at the interface.

A key input to the FE model is the flow stress of the two materials; pure copper $\mathrm{C} 11000(99.90 \% \mathrm{Cu})$ and pure cast $\mathrm{Al}$ which were obtained experimentally and used in the simulation. ${ }^{[145]}$ The experiment included torsion testing of the samples for which the test rig is shown in Figure 15. To obtain the appropriate stress-strain behavior of the materials, a room temperature torsion test was performed after a similar thermal cycle of AFSCE process (Figure 15c) and the torque-twist data were converted to the stress-strain curve using the technique presented by Khoddam et al. ${ }^{[175]}$ The torsion test sample and its heat treatment enclosure are shown in Figure 15a. The flow behaviors were also represented using the following analytical expressions for aluminum and copper, respectively:

Aluminium $\sigma=100.5 e^{0.2097 \varepsilon}-107.1 e^{(-10.96 \varepsilon)}$

Copper $\sigma=359.1 e^{0.0463 \varepsilon}-250 e^{(-1.316 \varepsilon)}$

Where, $\sigma(\mathrm{Mpa})$ and $\varepsilon$ are flow stress and strain, respectively, in a uniaxial loading. The mathematical models and experimental constitutive data are shown in Figure 15b.

Using the DBT's FE model, a large and uniform effective plastic strain was found at the interface with $1 \mathrm{~mm}$ sample thickness, $0.6 \mathrm{~mm}$ clearance between die and the punch and $0.1 \mathrm{~mm}$ fillet radii of the tools.$^{[150]}$ Thus a setup made with these parameters was used to design the experiment and to measure the strength of the bonding while a cohesive zone model was used to inversely estimate the shear stresses during the failure at the interface. ${ }^{[151]}$

\subsection{FE Characterization of FRMMC}

An important feature of "fiber reinforced metal matrix composite" (FRMMC) is that the fabricated metal-composite has zero degrees of freedom. The composite components are mechanically interlocked together. Obviously, adding other modes of bonding (e.g., gluing, metallurgical, welding, etc.) would increase the integrity of the composite. A closed form
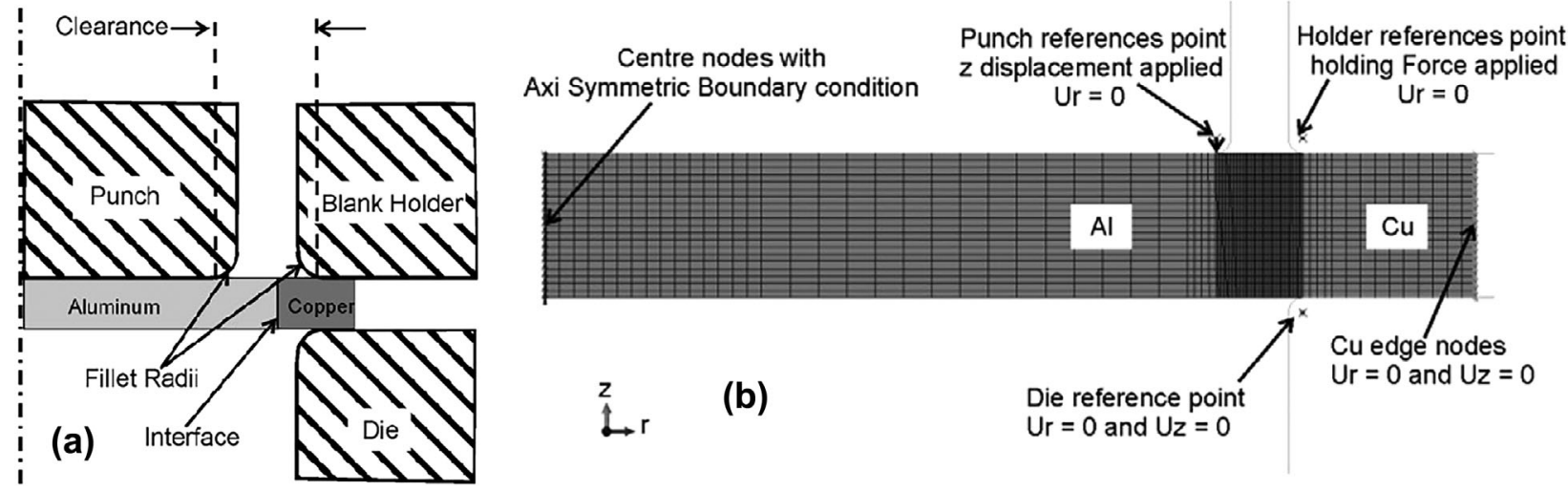

Figure 14. a) Schematics of DBT model b) meshed 2D axisymmetric numerical model with applied boundary condition. (Reproduced with permission. ${ }^{[150]} 2015$, Elsevier). 


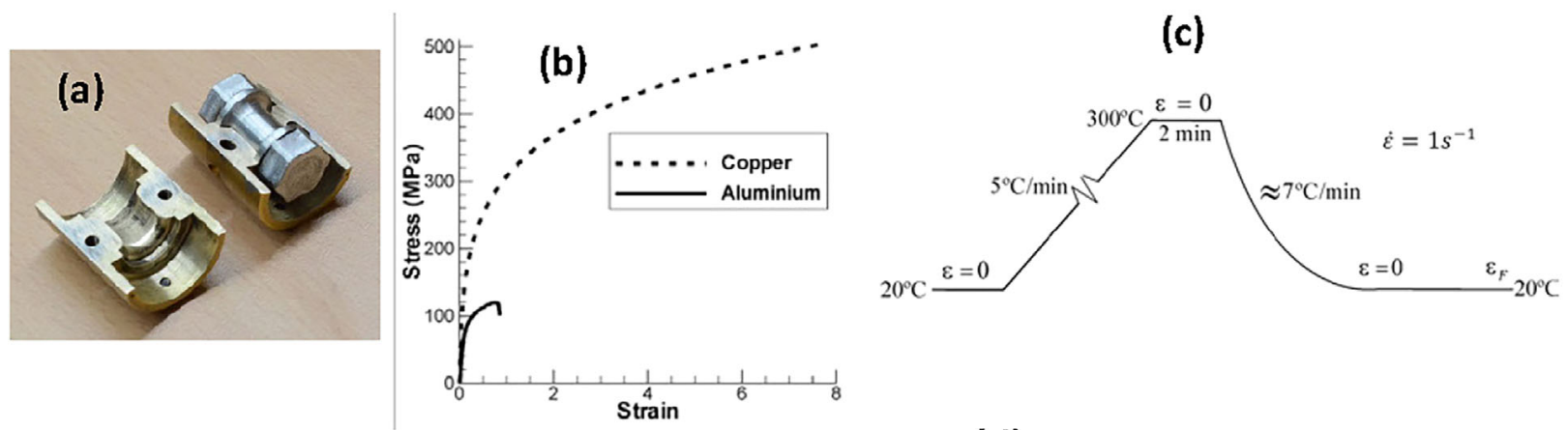

(d)

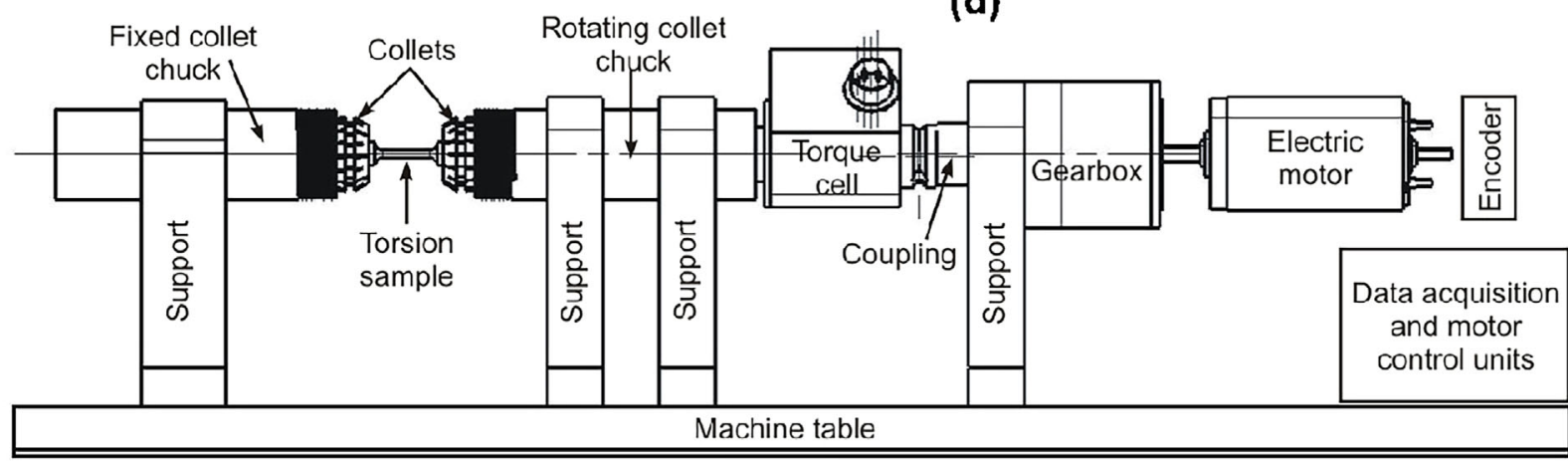

Figure 15. Warm torsion test a) an aluminum torsion test sample inside the heating conduction enclosure, b) estimated and measured stress-strain of copper and aluminum of this study at $300^{\circ} \mathrm{C}$, and c) thermal cycle of the sample prior to torsion (Inset c reproduced with permission from ref. [150], 2015, Elsevier) and d) torsion rig. ${ }^{[176]}$

derivation was developed by Khoddam et al. ${ }^{[149]}$ to analyze FRMMC. The closed form solution can be used to characterize the average work hardening in each component of the composite. Another numerical model was also employed to investigate the heterogeneous properties of the components in more detail, stress and friction development at the interface and to evaluate the process requirements, such as the required torque-twist to fabricate a given composite. Kim et al. developed a detailed FE model to characterize a stainless steel-copper (SS-Cu) FRMMC sample and to study the parameters of the hybrid-metal. ${ }^{[177]}$ Typical results obtained from the simulations using the dedicated finite element model are shown in Figure 16. ${ }^{[177]}$

\subsection{AM Based Alloy-Alloy Bond}

AM is commonly used to bond alloys to produce all the contact types shown in Figure 10. Despite the manufacturing category used (i.e., powder bed, powder feed, or wire feed), modeling of the bond is complex due to the multi-physics nature of the processing conditions. The complexity of the challenging task may be better understood by considering the phenomenological formation of heterogeneous pores, non-uniform thermal distributions, multiphysics behavior, induced residual stresses, resulting heterogeneous material properties etc.

\section{Applications in Various Fields}

There is a growing demand for hybrid and composite metals for many industrial, electrical, electronics, medical and daily life applications where the properties of one material alone are not adequate to fulfil the requirements. ${ }^{[1 \mathrm{a}]}$ Examples of these are aerospace industry, chemical/petroleum processing plants, wearable and medical equipment, electric cables, heat exchangers, and cooking utensils. For many cases of metal-composite joining, the effective bond between the constituents can be fulfilled by either a traditional or an innovative manufacturing technique (e.g., cold welding, diffusion welding, explosive welding, and friction stir welding or using an appropriate type of additive manufacturing). For many applications, the joining processes are considered as secondary manufacturing methods. A number of selected applications for metal-composites will be presented next.

\subsection{Diffusion Bonding}

Use of diffusion bonded parts in military aircraft includes fuselage frames, outboard and inboard actuator fittings, bulkhead, main landing gear trunnion and nacelle frames which are made of titanium and super alloys. The process reduces the required amount of rare materials. ${ }^{[102]}$ However, diffusion bonding is an expensive process, which requires a vacuum furnace to perform the welding and to be sufficiently large to include the whole part inside the furnace. Moreover, a careful surface preparation is required that is still challenging for certain materials such as aluminum alloys. In recent years, new metal joining techniques and their applications have been increased in medical, electronics, aerospace, chemical processing plants and structural applications. 


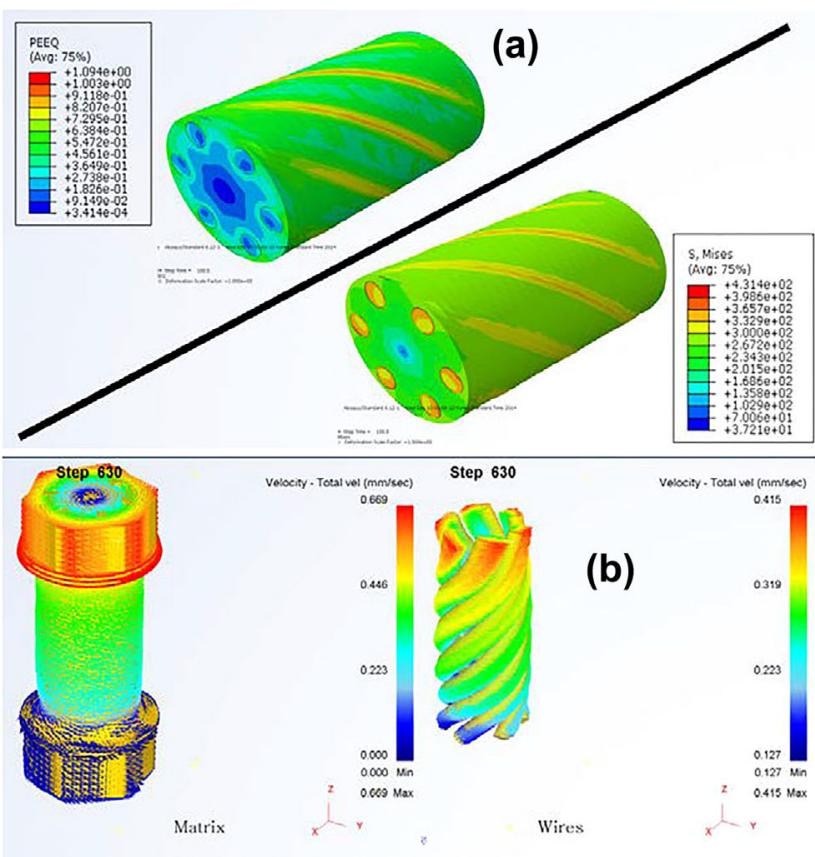

- Outer velocity is higher than the inner velocity in the matrix and wires.
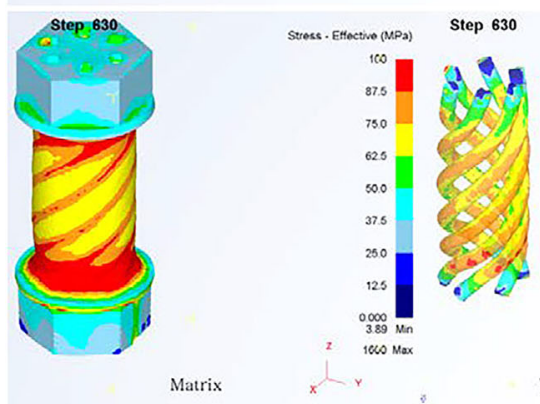

\section{(c)}

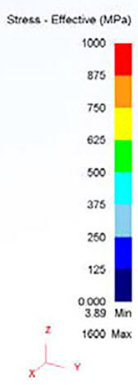

- Spiral deformation on the surface (i.e. Al matrix) is found.

- The matrix stress is much smaller than the wire stress.
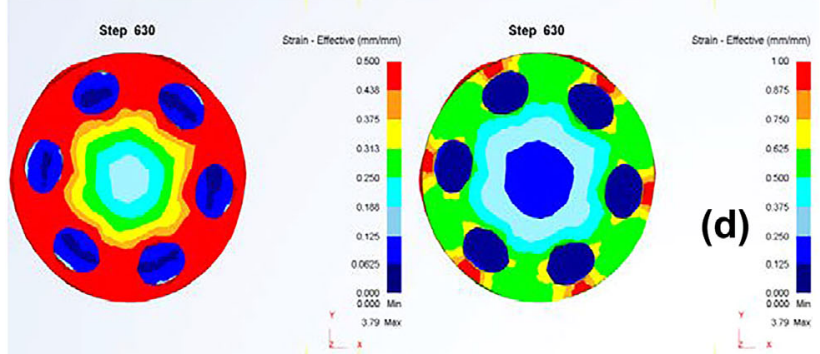

- Matrix deforms more, i.e. strain in the matrix is higher than that in the wires. The stress distribution is reverse.

- Two figures above are the same ones except the contour scale.

Figure 16. ABAQUS simulations of FRMMC sample by Kim et al. a) top and bottom insets are effective stress distribution in $\mathrm{Cu}$ matrix and SS fiber, respectively, subjected to simple torsion, b) velocity distribution in the Cu matrix and SS wires, c) effective stress distribution in Cu matrix and SS wires, and d) effective stress distribution in a cross-section of the FRMMC sample (Reproduced with permission from Kim et al., ${ }^{[177]}$ personal communication).

\subsection{Additive Manufacturing}

Both cold and thermal spray techniques have been used to incorporate metal-composite deposition in AM processes. Cold spray deposition enables non-thermal freeform to fabrication of metal-composites and can be regarded as a type of additive manufacturing. It eliminates high-temperature processing, which is needed for similar methods such as sintering based AM. It also eliminates the ecologically unfriendly chemicals which are used for electroplating.

Ultrasonic Additive Manufacturing (UAM) is currently available as a commercial technology. ${ }^{[154]}$ Thanks to its solidstate nature, UAM is suitable for joining dissimilar metals without the formation of brittle intermetallics as seen in fusion processes. UAM has been used successfully to bond several combinations of metals, most commonly $\mathrm{Al} / \mathrm{Cu}, \mathrm{Al} / \mathrm{Fe}$, and $\mathrm{Al} / \mathrm{Ti}$. Less common types with combinations such as $\mathrm{Ta} / \mathrm{Fe}$, $\mathrm{Ag} / \mathrm{Au}$, and $\mathrm{Ni} /$ stainless steel are also achievable using UAM. From a purely theoretical perspective, given enough ultrasonic power, the process should be able to bond any dissimilar metals.

Samples fabricated by UAM are shown in Figure 17. Bonding of the 3D "radio frequency" sensor to the catheter, shown in Figure 17c, enables its smarter use for medical applications.

\subsection{Intense Pulsed Light Sintering}

An intense pulsed light (IPL) process employs a xenon flash lamp to sinter copper nano-ink printed on low-temperature

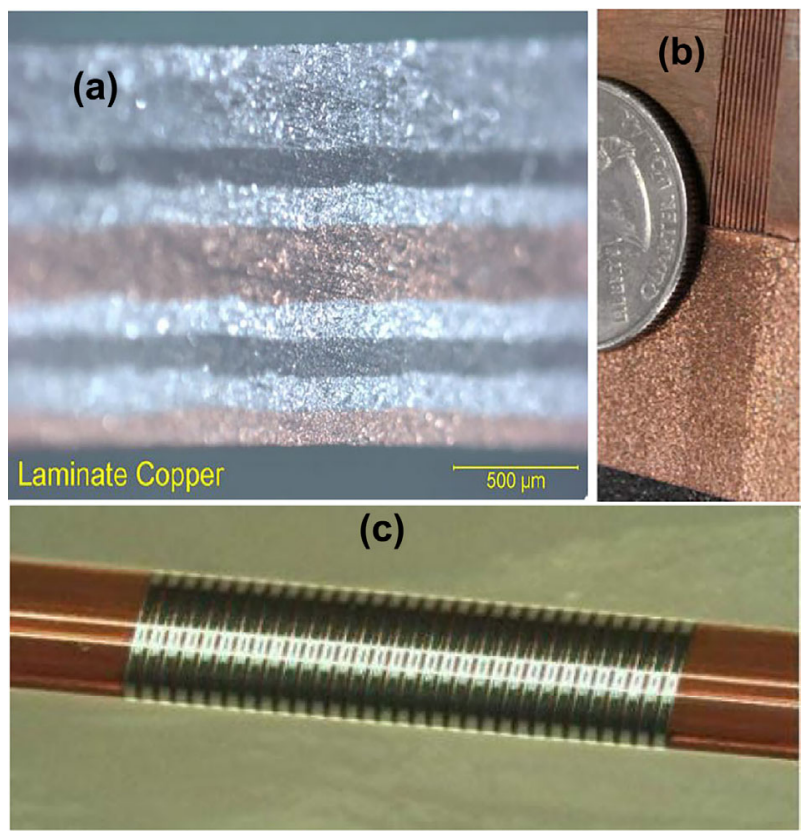

Figure 17. Sample metal-composites fabricated by, a) UAM Laminate Copper; 50x and b). UAM printing of parts that include embedded sensors/electronics, dissimilar metals, and/or complex internal geometry (Photos courtesy of Fabrisonic LLC) and c) printing a 3D radio frequency sensor on catheter (Photo courtesy of OPTOMEC). 


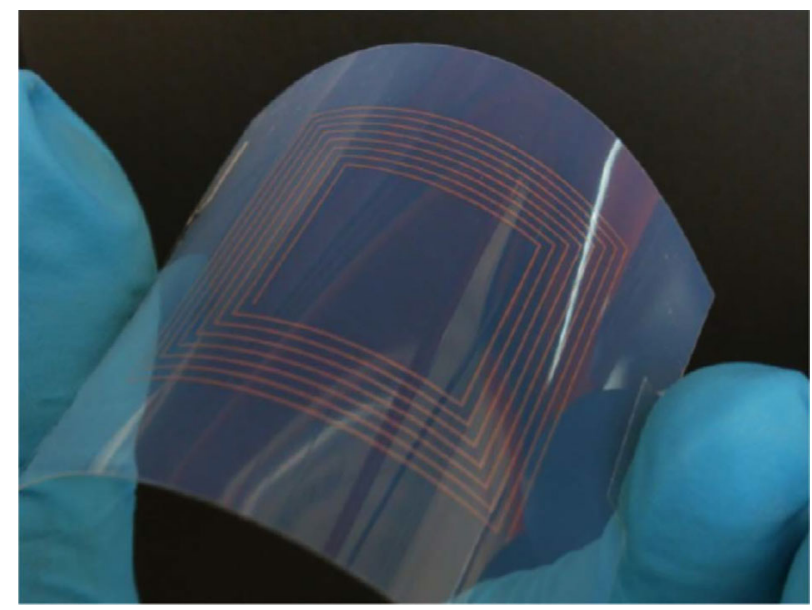

Figure 18. An inkjet-printed "radio frequency identification" (RFID) tag as a coil pattern (Reproduced with permission. ${ }^{[181]} 2014$, American Chemical Society ACS).

polymer substrates at room temperature and ambient conditions. ${ }^{[178]}$ An extremely short duration of IPL ( $\left.2 \mathrm{~ms}\right)$ is enough to sinter copper nano-ink without damaging the polymer substrates. This is potentially ideal for several "printed electronics" systems and many multi-disciplinary applications such as smart tags for "internet of things", $[179,180]$ and is also feasible for inkjet printing. Kang et al. ${ }^{[181]}$ demonstrated intense pulsed light (IPL) sintering of inkjet-printed $\mathrm{CuO}$ layers on a primer-coated porous PET substrate to convert the electrically insulating $\mathrm{CuO}$ into conductive $\mathrm{Cu}$ by adding conductive layers in less than $1 \mathrm{~s}$ after the printing process. The lowest resistivity of IPL sintered $\mathrm{Cu}$ layers was $\approx 55.4 \mathrm{n} \Omega \mathrm{m}$ which is $\approx 30 \%$ of bulk Cu conductivity. They reported a sheet resistance of $0.132 \Omega \mathrm{m}^{-2}$ and a layer thickness of $420 \mathrm{~nm}$ which was IPL-sintered at $8 \mathrm{~J} \mathrm{~cm}^{-2}$. To verify the applicability of the proposed IPL sintering method, a RFID coil pattern was inkjetprinted and sintered as shown in Figure 18 (using a single pulse of $4.5 \mathrm{~J} \mathrm{~cm}^{-2}$ ).

\subsection{Conductive Metal Based Inks}

Based on the printed electronics technology, a number of innovative solutions have been developed which rely on bonding of nanosilver inks (Ag - DDA and Ag-PVP) and liquid metal inks (EGaIn and $\mathrm{Bi}_{35} \operatorname{In}_{48.6}$ $\mathrm{Sn}_{16} \mathrm{Zn}_{0.4}$ ) to their substrate. ${ }^{[182]}$ The conductivity for the nano-silver and the liquid metal inks is typically between $6.25 \times 10^{6}$ to $3.45 \times 10^{7}$ and $3.4 \times 10^{6}$ to $7.3 \times 10^{6} \mathrm{~S} / \mathrm{m}$, respectively. ${ }^{[183]}$ Examples of these include tissue engineering, implantable devices and wearable bioelectronics. ${ }^{[182]}$ Wang and Liu ${ }^{[182]}$ have presented interesting new applications for "printed electronics" using liquid metal technologies. Images of a "liquid metal roller- ball pen" (LMRP) and its sample conductive tracks ${ }^{[184]}$ are shown in Figure 19.

\subsection{Stretchable Electronics for Wearable and Body-Implantable Devices}

For many applications of a metal-composite, such as electrical systems, the stability of the mechanical and electrical properties is essential. Typical examples of the case are stretchable and wearable sensors, actuators, energy storage and energy harvesting devices. Jin et al. ${ }^{[185]}$ developed a "stretchable loudspeaker" using Liquid Metal Microchannel. Their system employed a liquid metal coil of Galinstan which operates by the electromagnetic interaction between the liquid metal coil and a Neodymium (Nd) magnet. A key parameter for the device's consistent performance is the stability of the metal-composite's electrical resistivity during a two dimensional stretch. The system demonstrated a mechanical stability under $50 \%$ uniaxial and $30 \%$ biaxial strains. Fabrication and components of the acoustic device are shown in Figure 20.

\subsection{Turbine Parts in Aerospace Industries}

Specific parts of a turbine are required to stand for a very high temperature of approximately 1500 to $1800^{\circ} \mathrm{C}^{[186]}$ The high temperature melting super alloys are expensive but by studying the temperature variation in a single part, it is possible to manufacture a hybrid metal with a combination of high temperature and low temperature melting materials. The hybrid turbine router ${ }^{[187]}$ and hybrid gas turbine blade ${ }^{[186 b]}$ were invented to increase the fuel economy in aerospace applications. They save a large amount of operational costs since they allow an increase in the turbine operating temperature, which varies
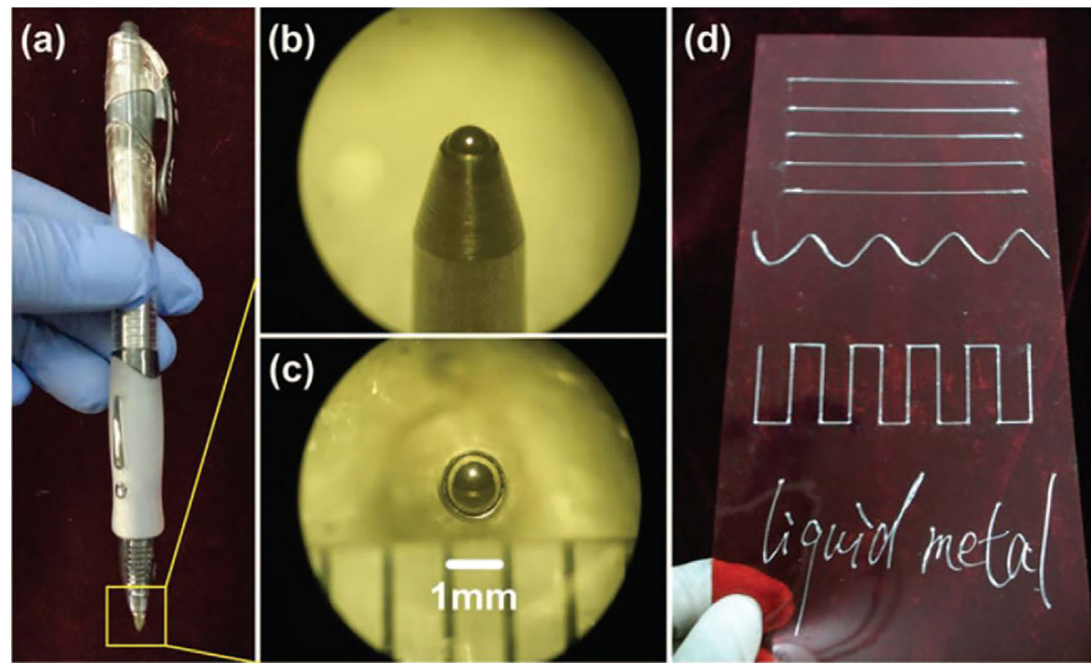

Figure 19. a) A roller-ball pen with liquid metal ink. b) and c) two views of the pen nib. d) the conductive tracks produced by the LMRP, containing lines, shapes, fold line and scripts. (Reproduced witpermission of authors: Y. Zheng, Q. Zhang, J. Liu, AIP Advances 2013, 3, 112117, AIP Publishing ${ }^{[84]}$. 

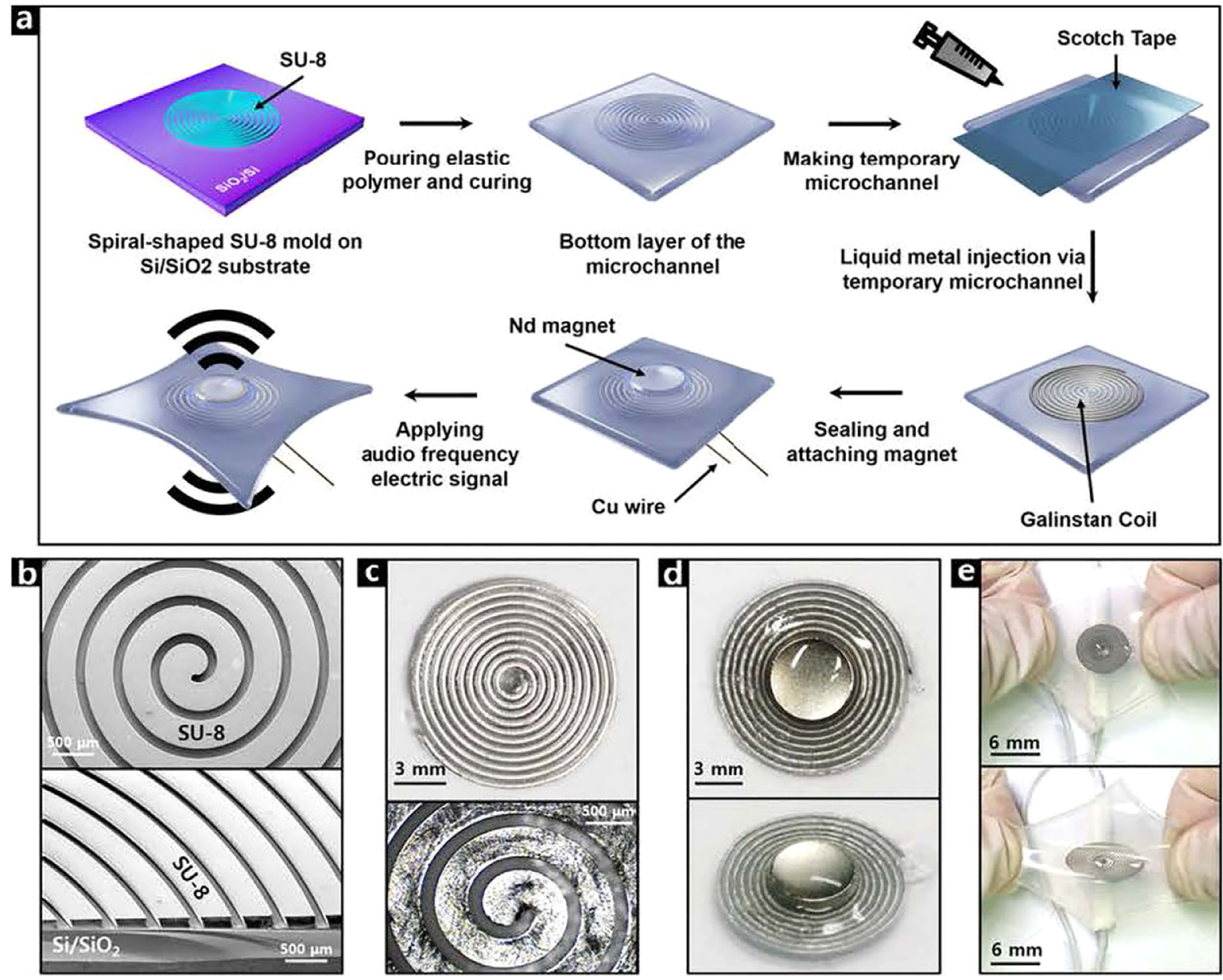

Figure 20. Making of a stretchable acoustic device (reproduced with permission from. ${ }^{[185]}$ ). a) Schematic of the metal-composite based system. b) SEM images of SAD's microchannel mold. Images of c) Galinstan microchannel, d) a SAD assembly, and e) SAD manually-stretched.

throughout the turbine. Therefore, hybrid metals are an economically viable solution to manufacture effective gas turbine parts. ${ }^{[186 b, 187]}$

\section{Conclusions and Future Outlook for Metal Based Hybrid Materials}

In practice, the innovative joining methods start at a bench scale in research labs and need to fulfil several criteria before they can be adopted at a production level. A large combination of metals, materials and properties exist in a metal-composite design context which can be employed to develop new metalcomposites for novel applications. The barriers to achieve these include our limited understanding of the multi-disciplinary interactions between the materials and properties. In a narrow spectrum of properties such as bonding strength, a small number of models exist with limited predictability. The gap is much wider when it comes to other properties, which are needed to produce functional materials.

An interesting example is the use of AM to bond "functional circuits" onto both planar and non-planar substrates, although $3 \mathrm{D}$ printing is commonly perceived as a "complete part builder" for a planar substrate. This key paradigm shift extends the scope of AM solutions to include the ability to print conformal electronics, including sensors, antennas and flexible circuits onto substrates produced by traditional manufacturing techniques.

The promises of metal-composites can be fulfilled only when effective bonding is established. The bonding strength could govern the overall strength of the composite. However, other properties, such as electrical and thermal conductivity, are the primary objective for several applications. In either case, it is important to understand the parameters of the bonding, both theoretically and experimentally.

This review has presented a number of experimental and analytical models for several bonding types and techniques and discussed their characterization methods and applications.

Examples were presented for some bonding methods, such as Additive Manufacturing, that can co-exist with conventional manufacturing techniques to enhance existing 2D and 3D substrates with conformal electronics and to open new doors for "printed electronics".

In the absence of a reliable predictive bond model, several process parameters should be identified experimentally to create an effective bonding at the interface. These include pressure, 
elevated temperature, time, and shear vibration. Due to the empirical nature of the identification, the optimized parameters are only applicable to the particular joining technique.

\section{Conflict of Interest}

The authors declare no conflict of interest.

\section{Keywords}

Additive manufacturing, Hybrid materials, Metal-composites, Modeling and characterization, Printed electronics

Received: January 16, 2018

Revised: April 11, 2018

Published online: May 23, 2018

[1] a) M. F. Ashby, Y. J. M. Bréchet, Acta Mater. 2003, 51, 5801; b) M. F. Ashby, Materials Selection in Mechanical Design, ButterworthHeinemann, Oxford, UK 2004.

[2] T. Clyne, P. Withers, An Introduction to Metal Matrix Composites, Cambridge University Press, Cambridge, UK 1995.

[3] D. Lloyd, Int. Mater. Rev. 1994, 39, 1.

[4] A. Mortensen, J. Llorca, Annu. Rev. Mater. Res. 2010, 40, 243.

[5] T. Christman, A. Needleman, S. Suresh, Acta Metall. 1989, 37, 3029.

[6] S. B. Sinnott, E. C. Dickey, Mater. Sci. Eng. R: Rep. 2003, 43, 1.

[7] Z. Spitalsky, D. Tasis, K. Papagelis, C. Galiotis, Prog. Polym. Sci. 2010, 35, 357.

[8] W. A. Curtin, B. W. Sheldon, Mater. Today 2004, 7, 44.

[9] E. T. Thostenson, Z. Ren, T.-W. Chou, Compos. Sci. Technol. 2001, 61, 1899.

[10] S. Bakshi, D. Lahiri, A. Agarwal, Int. Mater. Rev. 2010, 55, 41.

[11] K. P. So, X. Liu, H. Mori, A. Kushima, J. G. Park, H. S. Kim, S. Ogata, Y. H. Lee, J. Li, Extreme Mech. Lett. 2016, 8, 245.

[12] J. F. Flumerfelt, PhD Thesis, lowa State University, Ames, IA 1998, p. 154.

[13] J. Song, A. Kostka, M. Veehmayer, D. Raabe, Mater. Sci. Eng. A 2011, 528, 2641.

[14] I. E. Anderson, E. M. White, R. Dehoff, Curr. Opin. Solid State Mater. Sci. 2018, 22, 8 .

[15] A. Misra, H. Krug, Adv. Eng. Mater. 2001, 3, 217.

[16] L. Tian, A. Russell, T. Riedemann, S. Mueller, I. Anderson, Mater. Sci. Eng. A 2017, 690, 348.

[17] J. E. Allison, G. S. Cole, JOM 1993, 45, 19.

[18] J. F. Boylan, W. J. Boyle, K. M. Magrini, S. J. Huter, Google Patents, 2004

[19] N. Takeda, S. Minakuchi, Y. Okabe, J. Solid Mech. Mater. Eng. 2007, $1,3$.

[20] H. Hanninen, P. Aaltonen, A. Brederholm, U. Ehrnstén, H. Gripenberg, A. Toivonen, J. Pitkanen, I. Virkkunen, Espoo 2006, VTT Tiedotteita - Research Notes 2347, Julkaisija Utgivare Publisher, Otakaari, Finland.

[21] A. Markov, H. Guerboukha, M. Skorobogatiy, JOSA B 2014, 31, 2587.

[22] W. Chen, Z. Liu, J. Schroers, Acta Mater. 2014, 62, 49.

[23] A. Misra, M. Demkowicz, X. Zhang, R. Hoagland, JOM 2007, 59, 62.

[24] I. Beyerlein, A. Caro, M. Demkowicz, N. Mara, A. Misra, B. Uberuaga, Mater. Today 2013, 16, 443.

[25] L. Tian, A. Russell, I. Anderson, J. Mater. Sci. 2014, 49, 2787.

[26] A. M. Russell, L. S. Chumbley, Y. Tian, Adv. Eng. Mater. 2000, 2, 11.
[27] A. K. Kaw, Mechanics of Composite Materials, CRC Press, Boca Raton, FL, USA 2005.

[28] I. J. Beyerlein, M. J. Demkowicz, A. Misra, B. P. Uberuaga, Prog. Mater. Sci. 2015, 74, 125.

[29] L. Zou, C. Yang, Y. Lei, D. Zakharov, J. M. Wiezorek, D. Su, Q. Yin, J. Li, Z. Liu, E. A. Stach, Nat. Mater. 2018, 17, 56.

[30] J. Bevk, J. P. Harbison, J. L. Bell, J. Appl. Phys. 1978, 49, 6031.

[31] L. Tian, H. Kim, I. Anderson, A. Russell, Mater. Sci. Eng. A 2013, 570, 106.

[32] ASM. International, C. Handbook, Metal Handbook, ASM International, Materials Park, Ohio 1990

[33] A. Shaw, L. Tian, A. M. Russell, Br. J. Appl. Sci. Technol. 2016, 15, 1.

[34] L. Tian, I. Anderson, T. Riedemann, A. Russell, Powder Technol. 2017, 308, 84.

[35] L. Tian, I. Anderson, T. Riedemann, A. Russell, Acta Mater. 2014, 77, 151.

[36] L. Tian, I. Anderson, T. Riedemann, A. Russell, H. Kim, Electric Power Syst. Res. 2013, 105, 105.

[37] F. U. Flores, D. N. Seidman, D. C. Dunand, N. Q. Vo, “Development of High-Strength and High-Electrical-Conductivity Aluminum Alloys for Power Transmission Conductors", presented at TMS Annual Meeting a Exhibition, Phoenix, AZ, USA 2018.

[38] C. L. Trybus, W. A. Spitzig, Acta Metall. 1989, 37, 1971.

[39] J. D. Verhoeven, W. A. Spitzig, L. L. Jones, H. L. Downing, C. L. Trybus, E. D. Gibson, L. S. Chumbley, L. G. Fritzemeier, G. D. Schnittgrund, J. Mater. Eng. 1990, 12, 127.

[40] S. I. Hong, Adv. Eng. Mater. 2001, 3, 475.

[41] A. M. Russell, L. S. Chumbley, Y. Tian, Adv. Eng. Mater. 2000, 2, 11.

[42] A. M. Russell, T. Lund, L. S. Chumbley, F. A. Laabs, L. L. Keehner, J. L. Harringa, Compos. Part A-Appl. S 1999, 30, 239.

[43] K. Xu, A. M. Russell, L. S. Chumbley, F. C. Laabs, V. B. Gantovnik, Y. Tian, J. Mater. Sci. 1999, 34, 5955.

[44] K. Xu, K. Wongpreedee, A. M. Russell, J. Mater. Sci. 2002, 37, 5209.

[45] a) W. Yu, X. Wang, H. Zhao, C. Ding, Z. Huang, H. Zhai, Z. Guo, S. Xiong, J. Alloys Compd. 2017, 702, 199; b) W. Yu, H. Zhao, X. Wang, L. Wang, S. Xiong, Z. Huang, S. Li, Y. Zhou, H. Zhai, J. Alloys Compd. 2018, 730, 191.

[46] L. Tian, PhD Thesis, Ames Laboratory (AMES), Ames, IA 2015.

[47] W. A. Spitzig, A. R. Pelton, F. C. Laabs, Acta Metall. 1987, 35, 2427.

[48] P. D. Funkenbusch, J. K. Lee, T. H. Courtney, Metall. Trans. A 1987, $18,1249$.

[49] C. L. Trybus, L. S. Chumbley, W. A. Spitzig, J. D. Verhoeven, Ultramicroscopy 1989, 30, 315.

[50] D. Raabe, U. Hangen, Compos. Sci. Technol. 1995, 55, 57.

[51] a) S. Brinckmann, T. Siegmund, Y. Huang, Int. J. Plast. 2006, 22, 1784; b) Y. Huang, S. Qu, K. C. Hwang, M. Li, H. Gao, Int. J. Plast. 2004, 20, 753.

[52] N. A. Fleck, G. M. Muller, M. F. Ashby, J. W. Hutchinson, Acta Metall. Mater. 1994, 42, 475.

[53] J. S. Stölken, A. G. Evans, Acta Mater. 1998, 46, 5109.

[54] M. Shell De Guzman, G. Neubauer, P. Flinn, W. D. Nix, MRS Proceedings 2011, 308, 613.

[55] D. J. Lloyd, Int. Mater. Rev. 1994, 39, 1.

[56] R. K. Abu Al-Rub, G. Z. Voyiadjis, Int. J. Plast. 2006, 22, 654.

[57] H. Gao, Y. Huang, W. D. Nix, J. W. Hutchinson, J. Mech. Phys. Solids 1999, 47, 1239.

[58] M. F. Ashby, Philos. Mag.: J. Theor. Exp. Appl. Phys. 1970, 21, 399.

[59] N. A. Fleck, J. W. Hutchinson, J. Mech. Phys. Solids 2001, 49, 2245.

[60] W. D. Nix, H. Gao, J. Mech. Phys. Solids 1998, 46, 411.

[61] H. Gao, Y. Huang, Int. J. Solids Struct. 2001, 38, 2615.

[62] L. Tian, A. Russell, I. Anderson, J. Mater. Sci. 2014, 49, 2787.

[63] M. J. Demkowicz, R. G. Hoagland, J. P. Hirth, Phys. Rev. Lett. 2008, $100,136102$. 
[64] Q. Yu, L. Qi, K. Chen, R. K. Mishra, J. Li, A. M. Minor, Nano Lett. 2012, 12, 887.

[65] H. R. Z. Sandim, M. J. R. Sandim, H. H. Bernardi, J. F. C. Lins, D. Raabe, Scr. Mater. 2004, 51, 1099.

[66] L. Tian, A. Russell, J. Chem. Phys. 2014, 140, 124706.

[67] L. Zhang, M. J. Demkowicz, Appl. Phys. Lett. 2013, 103, 061604.

[68] Y. Zhou, Physics Reports 2017, 720-722, 1.

[69] a) N. A. Mara, I. J. Beyerlein, J. Mater. Sci. 2014, 49, 6497; b) A. J. Vattré, N. Abdolrahim, K. Kolluri, M. J. Demkowicz, Scientific Reports 2014, 4, 6231; c) I. A. Ovid'ko, Phys Solid State 1999, 41, 1500.

[70] Y. Yao, T. Wang, C. Wang, Phys. Rev. B 1999, 59, 8232.

[71] M. A. Meyers, A. Mishra, D. J. Benson, Prog. Mater. Sci. 2006, 51, 427.

[72] a) Y. Wang, M. Chen, F. Zhou, E. Ma, Nature 2002, 419, 912; b) C. Suryanarayana, Int. Mater. Rev. 1995, 40, 41; c) C. C. Koch, Nanostruct. Mater. 1993, 2, 109.

[73] a) C. E. Carlton, P. J. Ferreira, Acta Mater. 2007, 55, 3749; b) H. Hahn, K. A. Padmanabhan, Philos. Mag. B 1997, 76, 559; c) C. Suryanarayana, D. Mukhopadhyay, S. N. Patankar, F. H. Froes, J. Mater. Res. 2011, 7, 2114.

[74] V. Yamakov, D. Wolf, S. R. Phillpot, A. K. Mukherjee, H. Gleiter, Nat. Mater. 2003, 3, 43.

[75] a) D. Raabe, M. Herbig, S. Sandlöbes, Y. Li, D. Tytko, M. Kuzmina, D. Ponge, P. P. Choi, Curr. Opin. Solid State Mater. Sci. 2014, 18, 253; b) A. Ma, F. Roters, D. Raabe, Acta Mater. 2006, 54, 2181; c) M. Chen, E. Ma, K. J. Hemker, H. Sheng, Y. Wang, X. Cheng, Science 2003, 300, 1275; d) M. Dao, L. Lu, R. J. Asaro, J. T. M. De Hosson, E. Ma, Acta Mater. 2007, 55, 4041.

[76] U. F. Kocks, Metall. Mater. Trans. B 1970, 1, 1121.

[77] V. G. Gryaznov, M. Y. Gutkin, A. E. Romanov, L. I. Trusov, J. Mater. Sci. 1993, 28, 4359.

[78] a) J. E. Carsley, J. Ning, W. W. Milligan, S. A. Hackney, E. C. Aifantis, Nanostruct. Mater. 1995, 5, 441; b) M. Y. Gutkin, I. A. Ovid'ko, Nanostruct. Mater. 1993, 2, 631; c) H. S. Kim, Scr. Mater. 1998, 39, 1057.

[79] N. Wang, Z. Wang, K. T. Aust, U. Erb, Acta Metall. Mater. 1995, 43, 519.

[80] L. Tian, Int. J. Metall. Met. Phys. 2017, 2, 1.

[81] H. Hahn, P. Mondal, K. A. Padmanabhan, Nanostruct. Mater. 1997, 9, 603.

[82] M. Y. Gutkin, I. A. Ovid'ko, C. S. Pande, Philos. Mag. 2004, 84, 847.

[83] R. A. Masumura, P. M. Hazzledine, C. S. Pande, Acta Mater. 1998, $46,4527$.

[84] H. S. Kim, Y. Estrin, M. B. Bush, Acta Mater. 2000, 48, 493.

[85] L. Li, P. M. Anderson, M.-G. Lee, E. Bitzek, P. Derlet, H. Van Swygenhoven, Acta Mater. 2009, 57, 812.

[86] a) A. K. Radchenko, Powder Metall. Met. Ceram. 2004, 43, 552; b) M. Strömgren, H. Aström, K. E. Easterling, Powder Metall. 1973, 16, 155; c) A. K. Radchenko, Powder Metall. Met. Ceram. 2004, 43, 447; d) I.-H. Moon, K.-H. Kim, Powder Metall. 1984, 27, 80; e) P. J. James, Powder Metall. 1977, 20, 21.

[87] I. E. Anderson, J. C. Foley, Surf. Interface Anal. 2001, 31, 599.

[88] Y. Deslandes, G. Pleizier, Powder Metall. 1999, 42, 325.

[89] B. J. Kellett, F. F. Lange, J. Am. Ceram. Soc. 1989, 72, 725.

[90] R. H. R. Castro, D. Gouvêa, J. Am. Ceram. Soc. 2016, 99, 1105.

[91] Y. Hirata, A. Hara, I. A. Aksay, Ceram. Int. 2009, 35, 2667.

[92] J. Liu, D. P. De Lo, Metall. Mater. Trans. A 2001, 32, 3117.

[93] J. Secondi, Powder Metall. 2002, 45, 213.

[94] S. Khoddam, T. Sapanathan, S. Zahiri, P. D. Hodgson, A. ZareiHanzaki, R. Ibrahim, Adv. Eng. Mater. 2015, 18, 501.

[95] M. Y. Bal'shin, Scientific Bases of Powder Metallurgy and Fiber Metallurgy, Metallurgiya Publishers, Moscow 1972, p. 335.

[96] R. Farley, F. H. H. Valentin, Powder Technol. 1968, 1, 344.

[97] K. E. Easterling, A. R. Thölén, Powder Metall. 1973, 16, 112.
[98] D. Bortzmeyer, J. Mater. Sci. 1992, 27, 3305.

[99] I. Nikolakakis, N. Pilpel, Powder Technol. 1988, 56, 95.

[100] V. K. Golubev, K. G. Rabinovich, Strength Mater. 1999, 31, 625.

[101] E. Ryshkewitch, J. Am. Ceram. Soc. 1953, 36, 65.

[102] S. Kalpakjian, Manufacturing Engineering and Technology. AddisonWesley Publishing Company, Reading, MA 1992, pp. 888-890.

[103] V. Lysak, S. Kuzmin, J. Mater. Process. Technol. 2012, 212, 150.

[104] E. P. Degarmo, J. T. Black, R. A. Kohser, Materials and Processes in Manufacturing. John Wiley \& Sons, USA 2004, p. 969.

[105] C. Jianqiao, S. Takezono, L. Guangxia, T. Tanaka. Effect of laser cladding on fatigue strength of an alloy steel.

[106] J. Nilson, Sweden Patent 3,780,554, 1973.

[107] K. Osakada, M. Limb, P. Mellor, Int. J. Mech. Sci. 1973, 15, 291.

[108] N. Ahmed, J. Mech. Work. Technol. 1978, 2, 19.

[109] R. Sliwa, Mater. Sci. Eng. A 1991, 135, 259.

[110] R. Sliwa, J. Mater. Process. Technol. 1997, 67, 29.

[111] K. Y. Rhee, W. Y. Han, H. J. Park, S. S. Kim, Mater. Sci. Eng. A 2004, 384, 70.

[112] O. D. Neikov, S. S. Nabojchenko, I. B. Murashova, V. G. Gopienko, I. V. Frishberg, D. V. Lotsko, Handbook of Non-Ferrous Metal Powders. Technologies and Applications, Elsevier Science, Oxford 2009. pp. 5-44, https://doi.org/10.1016/B978-1-85617422-0.00001-X

[113] O. Bouaziz, H. S. Kim, Y. Estrin, Adv. Eng. Mater. 2013, 15, 336.

[114] I. J. Beyerlein, L. S. Tóth, Prog. Mater. Sci. 2009, 54, 427.

[115] M. I. Latypov, Y. Beygelzimer, R. Kulagin, V. Varyukhin, H. S. Kim, Mater. Res. Lett. 2015, 3, 161.

[116] Y. Beygelzimer, R. Kulagin, Y. Estrin, L. S. Toth, H. S. Kim, M. I. Latypov, Adv. Eng. Mater. 2017, 19. https://doi.org/10.1002/ adem. 201600873

[117] R. Kulagin, M. I. Latypov, H. S. Kim, V. Varyukhin, Y. Beygelzimer, Metall. Mater. Trans. A 2013, 44, 3211.

[118] R. Z. Valiev, Y. Estrin, Z. Horita, T. G. Langdon, M. J. Zehetbauer, Y. T. Zhu, JOM 2006, 58, 33

[119] O. Bouaziz, Y. Bréchet, J. D. Embury, Adv. Eng. Mater. 2008, 10, 24.

[120] D. Raabe, P.-P. Choi, Y. Li, A. Kostka, X. Sauvage, F. Lecouturier, K. Hono, R. Kirchheim, R. Pippan, D. Embury, MRS Bull. 2010, 35, 982.

[121] Y. Beygelzimer, Y. Estrin, R. Kulagin, Adv. Eng. Mater. 2015, 17, 1853.

[122] a) T. C. Lowe, Y. T. Zhu, S. L. Semiatin, D. R. Berg, in Investigations and Applications of Severe Plastic Deformation, Vol. 80 (Eds: T. Lowe, R. Valiev), Springer, Netherlands 2000, p. 347; b) T. Lowe, R. Z. Valiev, Investigations and Applications of Severe Plastic Deformation, Vol. 80, Springer, Berlin/Heidelberg, Germany 2000; c) M. Zehetbauer, R. Z. Valiev, Nanomaterials by Severe Plastic Deformation, Wiley Online Library, Berlin/Heidelberg, Germany 2004; d) R. Z. Valiev, M. J. Zehetbauer, Y. Estrin, H. W. Höppel, Y. Ivanisenko, H. Hahn, G. Wilde, H. J. Roven, X. Sauvage, T. G. Langdon, Adv. Eng. Mater. 2007, 9, 527; e) R. Z. Valiev, R. Islamgaliev, I. Alexandrov, Bulk Nanostructured Materials from Severe Plastic Deformation, Vol. 45, Pergamon, Berlin/Heidelberg, Germany 2000.

[123] G. E. Dieter, D. Bacon, Mechanical Metallurgy, Vol. 3, McGraw-Hill, New York, 1986.

[124] P. Prangnell, J. R. Bowen, P. Apps, Mater. Sci. Eng.: A 2004, 375, 178.

[125] V. M. Segal, Mater. Sci. Eng.: A 1995, 197, 157.

[126] a) V. Varyukhin, Y. Beygelzimer, S. Synkov, D. Orlov, Mater. Sci. Forum 2006, 503-504, 335; b) V. Varyukhin, Y. Beygelzimer, R. Kulagin, O. Prokof'eva, A. Reshetov, Mater. Sci. Forum 2010, 667-669, 31; c) Y. Beygelzimer, V. Varyukhin, S. Synkov, D. Orlov, Mater. Sci. Eng.: A 2009, 503, 14; d) Y. Beygelzimer, D. Orlov, A. Korshunov, S. Synkov, V. Varyukhin, I. Vedernikova, A. Reshetov, A. Synkov, L. Polyakov, I. Korotchenkova, Solid State Phenom. 2006, $114,69$. 
[127] P. W. Bridgman, The Physics of High Pressure, Bell, London, UK 1952 , p. 445.

[128] H. S. Kim, Mater. Sci. Eng.: A 2002, 328, 317.

[129] Y. Nishida, H. Arima, J.-C. Kim, T. Ando, Scr. Mater. 2001, 45, 261.

[130] C.-Y. Chou, S.-L. Lee, J.-C. Lin, C.-M. Hsu, Scr. Mater. 2007, 57, 972.

[131] a) V. S. Rao, B. Kashyap, N. Prabhu, P. Hodgson, Mater. Sci. Eng.: A 2008, 486, 341; b) B. Talebanpour, R. Ebrahimi, K. Janghorban, Mater. Sci. Eng.: A 2009, 527, 141.

[132] a) E. Cerri, P. P. De Marco, P. Leo, J. Mater. Process. Technol. 2009, 209, 1550; b) A. Ma, J. Jiang, N. Saito, I. Shigematsu, Y. Yuan, D. Yang, Y. Nishida, Mater. Sci. Eng.: A 2009, 513, 122; c) K. Nakashima, Z. Horita, M. Nemoto, T. G. Langdon, Mater. Sci. Eng.: A 2000, 281, 82.

[133] B. Mani, M. Jahedi, M. H. Paydar, Mater. Sci. Eng.: A 2011, 528, 4159.

[134] A. Rosochowski, L. Olejnik, Int. J. Mater. Form. 2008, 1, 483

[135] a) M. Zebardast, A. K. Taheri, J. Mater. Process. Technol. 2011, 211, 1034; b) P. Eslami, A. K. Taheri, Mater. Lett. 2011, 65, 1862; c) A. R. Eivani, A. K. Taheri, Mater. Lett. 2007, 61, 4110.

[136] a) A. P. Zhilyaev, T. G. Langdon, Prog. Mater. Sci. 2008, 53, 893; b) A. P. Zhilyaev, S. Lee, G. V. Nurislamova, R. Z. Valiev, T. G. Langdon, Scr. Mater. 2001, 44, 2753; c) A. Zhilyaev, G. Nurislamova, B.-K. Kim, M. Baró, J. Szpunar, T. Langdon, Acto Mater. 2003, 51, 753; d) A. Vorhauer, R. Pippan, Scr. Mater. 2004, 51, 921; e) M. Kawasaki, R. B. Figueiredo, T. G. Langdon, Acta Mater. 2011, 59, 308; f) A. Zhilyaev, S. Lee, G. Nurislamova, R. Valiev, T. Langdon, Scr. Mater. 2001, 44, 2753.

[137] W. B. Filho, J. Fogagnolo, C. Rodrigues, C. Kiminami, C. Bolfarini, A. Yavari, Mater. Sci. Eng.: A 2004, 375, 936.

[138] A. Yavari, C. Rodrigues, C. Cardoso, R. Valiev, Scripta Mater. 2002, 46, 711.

[139] A. Bachmaier, R. Pippan, Mater. Sci. Eng.: A 2011, 528, 7589.

[140] Z. Lee, F. Zhou, R. Valiev, E. Lavernia, S. Nutt, Scr. Mater. 2004, 51, 209.

[141] T. Tokunaga, K. Kaneko, K. Sato, Z. Horita, Scr. Mater. 2008, 58, 735.

[142] R. Kulagin, Y. Beygelzimer, Y. Ivanisenko, A. Mazilkin, H. Hahn, in IOP Conf. Ser.: Mater. Sci. Eng., IOP Publishing, Bristol, UK 2017, 194, 012045

[143] K. Kaneko, T. Hata, T. Tokunaga, Z. Horita, Mater. Trans. 2009, 50, 76.

[144] T. Sapanathan, S. Khoddam, S. Zahiri, A. Zarei-Hanzaki, R. Ibrahim, J. Mater. Sci. 2016, 51, 3118.

[145] T. Sapanathan, PhD Thesis, Monash University, Clayton Campus 2014

[146] T. Sapanathan, S. Khoddam, S. H. Zahiri, J. Alloys Compd. 2013, 571,85 .

[147] A. Shirzadi, in Microjoining and Nanojoining (Ed: Y. N. Zhou), Woodhead Publishing Limited, Cambridge 2004, p. 234

[148] D. G. Brandon, W. D. Kaplan, Joining Processes: An Introduction, Wiley-VCH, Weinheim, Germany 1997, 378.

[149] S. Khoddam, Y. Estrin, H. S. Kim, O. Bouaziz, Mater. Des. 2015, 85 p. 404.

[150] T. Sapanathan, R. Ibrahim, S. Khoddam, S. H. Zahiri, Mater. Sci. Eng. A 2015, 623, 153.

[151] A. Sova, S. Grigoriev, A. Okunkova, I. Smurov, Int. J. Adv. Manuf. Technol. 2013, 69, 2269.

[152] R. Raoelison, Y. Xie, T. Sapanathan, M. Planche, R. Kromer, S. Costil, C. Langlade, Add. Manuf. 2017, 19, 134.
[153] L. Liu, Z. Zhuang, F. Liu, M. Zhu, Int. J. Adv. Manuf. Technol. 2013, 69, 2131.

[154] A. G. Truog, PhD Dissertation, The Ohio State University, 2012.

[155] T. Sapanathan, S. Khoddam, S. Zahiri, A. Zarei-Hanzaki, Mater. Des. 2014, 57, 306.

[156] O. Vinogradov, Fundamentals of Kinematics and Dynamics of Machines and Mechanisms, CRC Press, Boca Raton, FL, USA 2000.

[157] T. Guess, R. Allred, F. Gerstle, J. Test. Eval. 1977, 5, 84.

[158] J. Lee, D. Bae, W. Chung, K. Kim, J. Lee, Y. Cho, J. Mater. Process. Technol. 2007, 187, 546.

[159] M. A. Sokolov, J. D. Landes, G. E. Lucas, Small Specimen Test Techniques, Vol. 4, ASTM International, West Conshohocken, PA, USA 2002.

[160] G. E. Lucas, J. Nucl. Mater. 1983, 117, 327.

[161] T. K. J. H. C. Kwon, S. C. Lim, M. S. Kim, Mater. Sci. Forum 2004, 449-452, 317.

[162] C. S. Hartley, Int. J. Mech. Sci. 1973, 15, 651.

[163] H. Tokuno, K. Ikeda, J. Mater. Process. Technol. 1991, 26, 323.

[164] a) B. Avitzur, R. Wu, S. Talbert, Y. Chou, J. Manuf. Sci. Eng. 1982, 104, 293; b) B. Avitzur, R. Wu, S. Talbert, Y. Chou, J. Manuf. Sci. Eng. 1986, 108, 205

[165] N. Chitkara, A. Aleem, Int. J. Mech. Sci. 2001, 43, 2857

[166] S. Berski, H. Dyja, G. Banaszek, M. Janik, J. Mater. Process. Technol. 2004, 153, 583.

[167] H. Haghighat, G. R. Asgari, Int. J. Mech. Sci. 2011, 53, 248.

[168] P. Kazanowski, M. E. Epler, W. Z. Misiolek, Mater. Sci. Eng.: A 2004, 369, 170.

[169] A. Khosravifard, R. Ebrahimi, Mater. Des. 2010, 31, 493.

[170] Y. Beygelzimer, A. Reshetov, S. Synkov, O. Prokof'eva, R. Kulagin, J. Mater. Process. Technol. 2009, 209, 3650.

[171] A. Farhoumand, P. D. Hodgson, S. Khoddam, X. Y. Fang, Mater. Sci. Eng. A 2013, 579, 217.

[172] S. Khoddam, A. Farhoumand, P. D. Hodgson, Mech. Mater. 2011, 43,684 .

[173] J. Dundurs, D. Sotiropoulos, Comput. Mech. 1998, 21, 300

[174] T. Sapanathan, R. Ibrahim, S. Khoddam, S. Zahiri, Adv. Mater. Res. 2014, 1016, 125.

[175] S. Khoddam, Y. C. Lam, P. F. Thomson, Steel Res. 1995, 66, 45.

[176] A. H. Shamdani, in Mechanical and Aerospace Engineering, PhD Thesis, Monash, Melbourne 2012, p. 224.

[177] H. S. Kim, Y. Estrin, J. Jung, personal communication, 2015.

[178] H.- S. Kim, S. R. Dhage, D.-E. Shim, H. T. Hahn, Appl. Phys. A 2009, 97, 791.

[179] J. Gubbi, R. Buyya, S. Marusic, M. Palaniswami, Future Gener. Comput. Syst. 2013, 29, 1645

[180] L. Atzori, A. lera, G. Morabito, Comput. Networks 2010, 54, 2787.

[181] H. Kang, E. Sowade, R. R. Baumann, ACS Appl. Mater. Interfaces 2014, 6, 1682.

[182] X. Wang, J. Liu, Micromachines 2016, 7, 206.

[183] L. Wang, J. Liu, Imaging Sci. Photochem. 2014, 32, 382.

[184] Y. Zheng, Q. Zhang, J. Liu, AIP Adv. 2013, 3, 112117.

[185] S. W. Jin, J. Park, S. Y. Hong, H. Park, Y. R. Jeong, J. Park, S.-S. Lee, J. S. Ha, Sci. Rep. 2015, 5, 11695.

[186] a) H. I. H. Saravanamuttoo, G. F. C. Rogers, H. Cohen, Gas Turbine Theory, Pearson Education, Toronto, Canada 2001; b) J. C. Schilling, Google Patents, 1997.

[187] B. A. Ewing, M. Herman, Google Patents, 1979. 